\title{
AMBIENTE CULTURAL, ACADEMIAS DE ARTE, ESTUDIOS Y TALLERES EN LA REGIÓN DE MURCIA DESDE FINALES DEL SIGLO XIX Y PRINCIPIOS DEL SIGLO XX.
}

\section{CULTURAL ENVIRONMENT, ACADEMY OF ARTS, STUDIES AND WORKSHOPS IN MURCIA REGION FROM LATE NENETEENTH CENTURY}

María Luisa Martínez León 1. Universidad Católica San Antonio de Murcia. España. martinez@ucam.edu

\section{RESUMEN}

Historia de los centros de enseñanza reglada, academias de arte, estudios, talleres y centros de reunión que existieron y ejercieron notable influencia en la escultura de finales del siglo XIX y principios del XX, cuya repercusión ha tenido y tiene gran importancia en el desarrollo de la escultura, escultores, pintores y otros artistas y que tuvieron su emplazamiento en Murcia. Focalizando la atención en la importancia que tiene el taller de Anastasio Martínez Hernández, centro con una gran actividad en diversas facetas artísticas, ubicado en el centro de Murcia, al que tuvieron acceso gran cantidad de artistas murcianos, cuya trascendencia nacional e internacional ha quedado reflejada en abundantes obras, revistas y escritos de su época y posteriores. Desarrolla este taller su labor docente y artística entre 1894 y 1933, y su repercusión tiene continuidad en numerosos artistas de nuestros días, descendientes y discípulos directos e indirectos de este taller.

PALABRAS CLAVE: arte, escultura, escultores, Martínez Hernández, talleres, gremios, academias.

\section{ABSTRACT}

This article focuses on the history of the centers of formal education, art academies, studios, workshops and meeting centers that existed and exerted considerable influence on the sculpture of the late nineteenth and early twentieth century. The impact of these centers has been and is still is of great importance in the development of sculpture, sculptors, painters and other artists based in Murcia. Focusing attention on the importance of the workshop of Anastasio Martínez Hernández, located in the center of Murcia, of which the national and international importance has been reflected in numerous works, journals and writings of his time and later. This workshop develops his teaching and artistic work between 1894 and 1933, and his impact continues in many artists of today, descendants and direct and indirect disciples of this workshop.

\footnotetext{
1 María Luisa Martínez León. Profesora de Artística, Plástica y Visual. Universidad Católica San Antonio. Departamento de Ciencias Sociales y de la Comunicación.
} 
KEY WORDS: art, sculpture, sculptors, Martínez Hernández, workshops, guilds, academies.

\section{Cómo citar el artículo:}

Martínez León, M. L. (2017). Ambiente cultural, academias de arte, estudios y talleres en la región de Murcia desde finales del siglo XIX y principios del siglo XX. Revista de Ciencias de la Comunicación e Información, 22(2), 13-36.

doi: http://doi.org/10.35742/rcci.2017.22(2).13-36

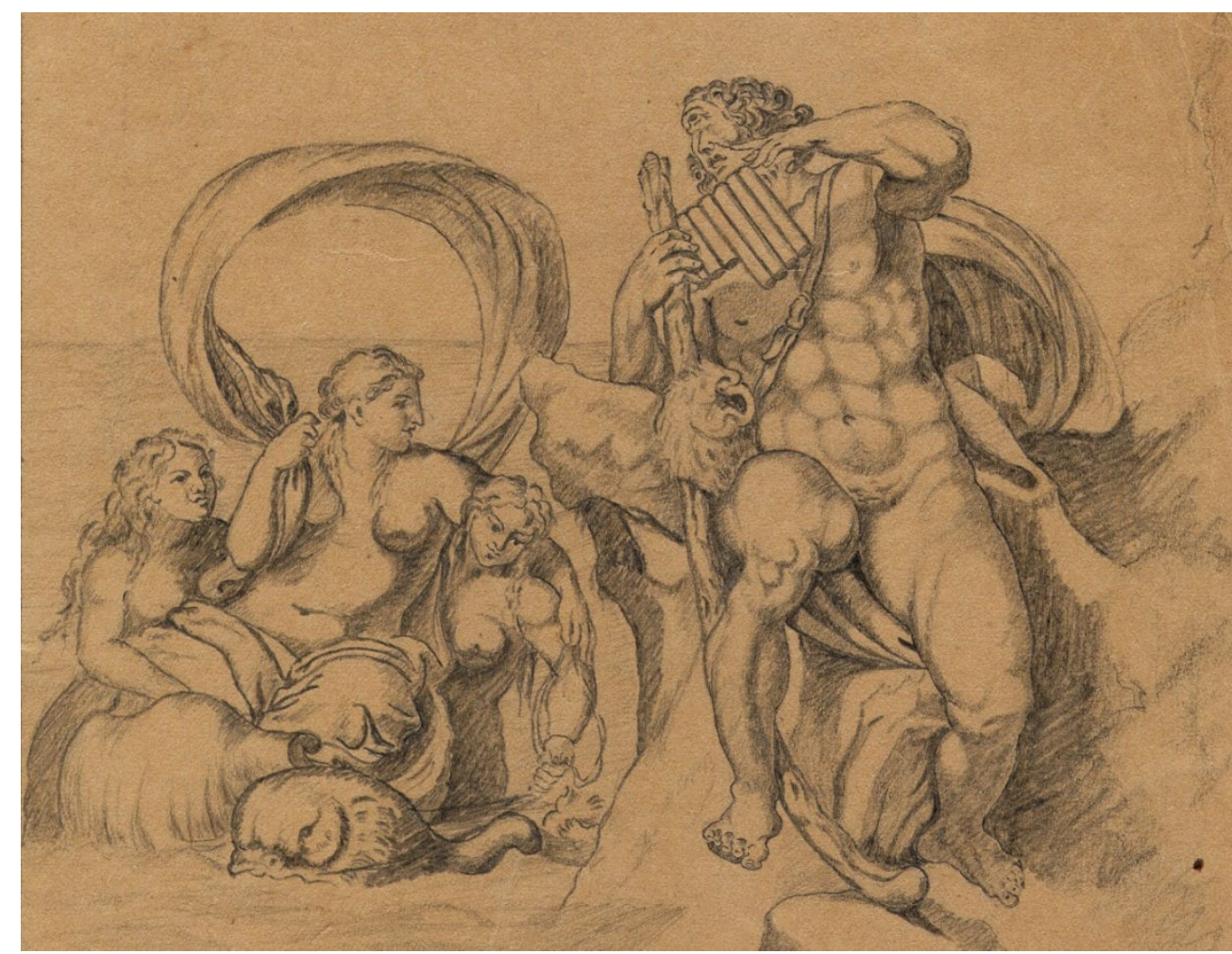

“Ciclope Polifemo”. Boceto para relieve. Lápiz/Papel. Colección Particular. Obra de Anastasio Martínez Hernández (1874-1933). 


\section{INTRODUCCIÓN}

Históricamente los centros existentes en esta época han desempeñado un papel vital en la historia del desarrollo de la plástica murciana. Aunque eran escasos los centros donde pudiesen formarse en cuestiones de arte con una edad avanzada y niveles superiores, Si existía la posibilidad de introducirse en este mundo a una temprana edad, entre los seis y los diez años, bien asistiendo a las clases de la Academia de Bellas Artes del Círculo de Amigos del País, del Círculo Católico de Obreros o del Círculo de Bellas Artes, bien como aprendiz en el taller de un pintor o de un escultor con un bagaje y una amplia trayectoria profesional, o en muchos casos acudiendo a ambos, como aprendiz en un taller y ampliando conocimientos en determinadas clases de arte de estos centros reglados. Estaba contemplada, y así se procedía, la posibilidad de solicitar y conseguir una beca para ampliar estos estudios con niveles superiores en otras provincias para los alumnos aventajados.

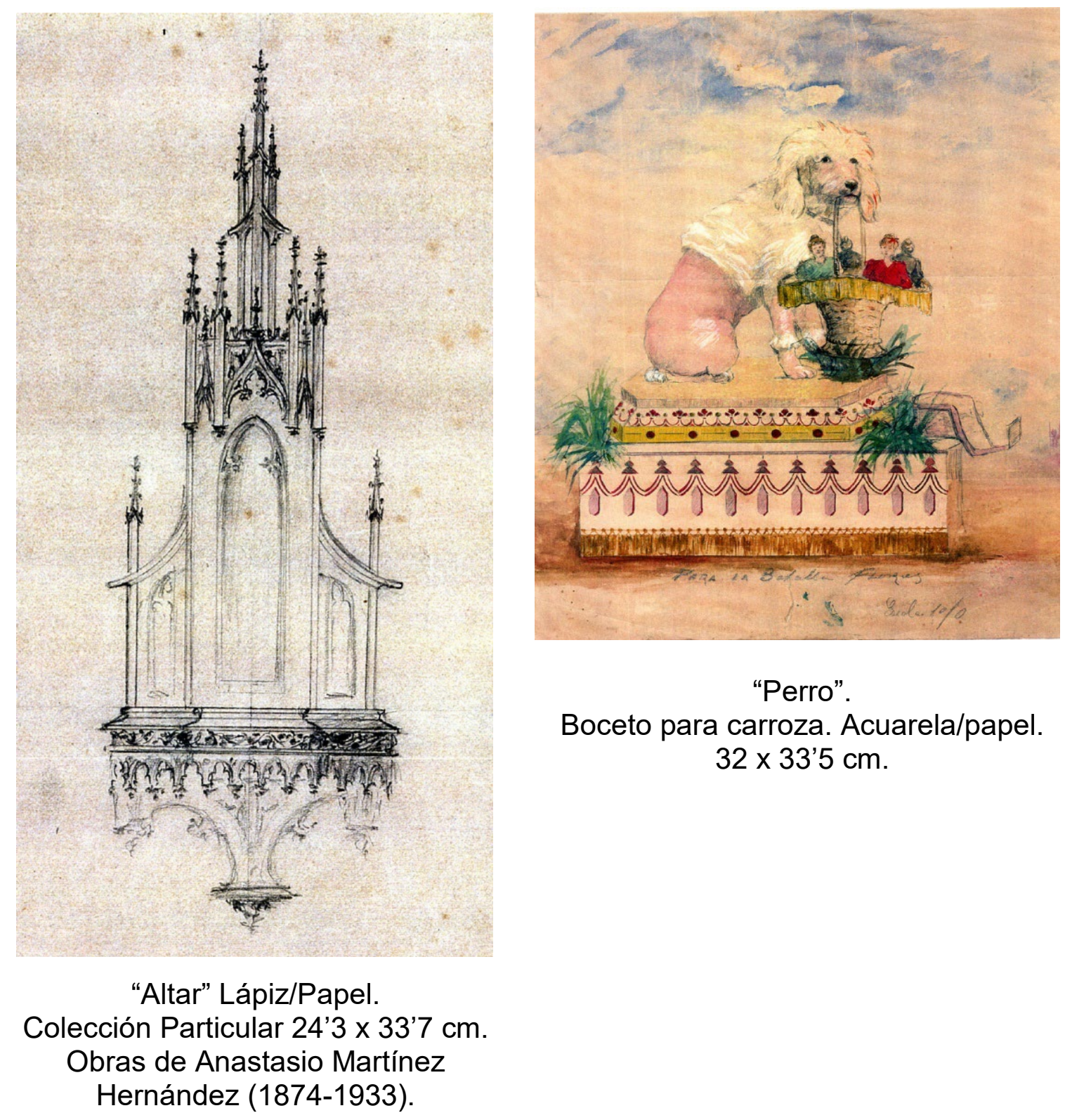


Los talleres de pintura, escultura y/o artesanías, estaban organizados como gremios, atendiendo a la capacidad o necesidad del trabajo que cada uno podía realizar. Generalmente se ingresaba en ellos como aprendiz, a una temprana edad, bien de manera voluntaria por requerimientos del maestro, bien por solicitud de los padres, que eran en muchos casos quienes así lo solicitaban para dar diferentes salidas a uno o varios de sus descendientes. Podemos encontrar en Murcia varios talleres relacionados con la pintura, pero referidos a la escultura es el de Anastasio Martínez Hernández el único que encontramos activo entre 1894 y 1920 . Posteriormente, a partir de esta fecha, bien entrado el siglo $X X$, es cuando comienzan a aflorar algunos otros, generalmente jóvenes discípulos del taller que se independizan. Las relaciones existentes entre los talleres, las tertulias y los artistas que en ellos trabajaban son esenciales y nos demuestran las estrechas uniones que se desarrollan en este ámbito poco profuso.

Actualmente no hay centros donde, de manera similar a como ocurre en otras disciplinas artísticas como la música (para la que si existen centros de enseñanza, los conservatorios y escuelas municipales de música, donde es requisito indispensable y necesario que los maestros y profesores que imparten enseñanzas en ellos estén especializados en estas materias), no ocurre esto con otras disciplinas en las que, es una curiosa controversia que dispongamos de centros de enseñanza superior en Artes, ciclos formativos superiores y universidad de Bellas Artes, en los que la edad mínima para ingresar es de 18 años, y sean totalmente inexistentes los centros de arte que nos inicien o tengan un nivel medio en estas mismas disciplinas y que permitan acceder a ellas con unos niveles apropiados a estos centros superiores.

\section{OBJETIVOS}

Uno de los objetivos principales que tratamos en este artículo es de comprender mejor la influencia y repercusión del taller del escultor de Anastasio Martínez Hernández sobre el quehacer artístico de su época y posteriores y las relaciones

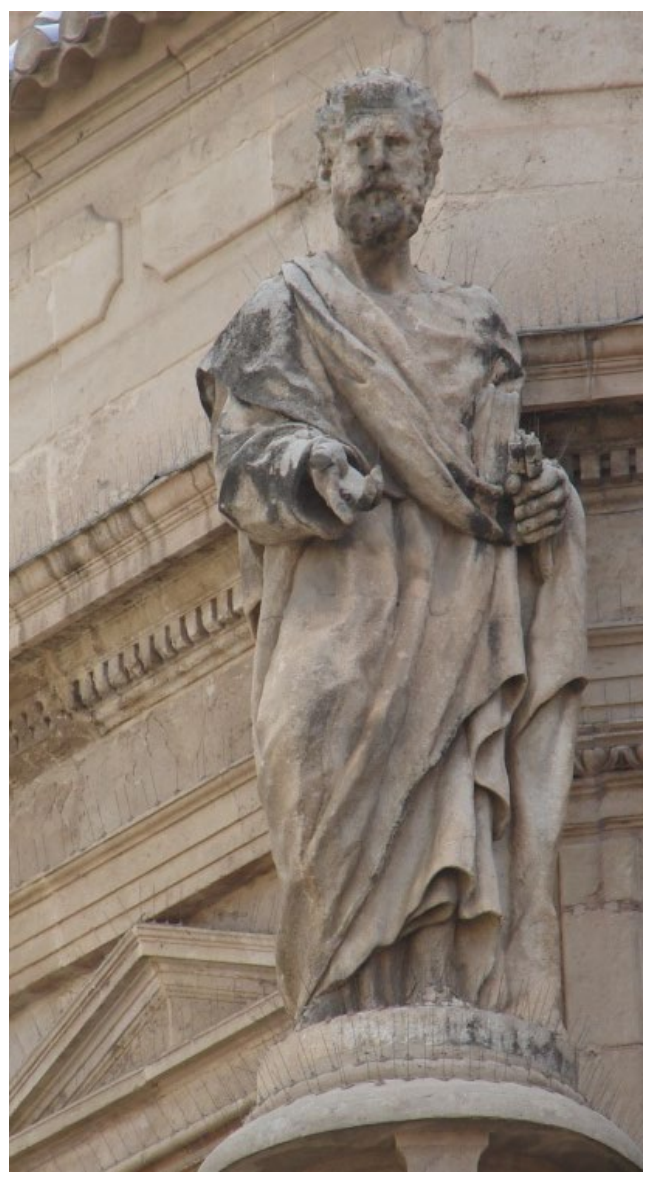

"San Pedro" Piedra. Fachada Catedral Murcia.

Obras de Anastasio Martínez Hernández (1874-1933).

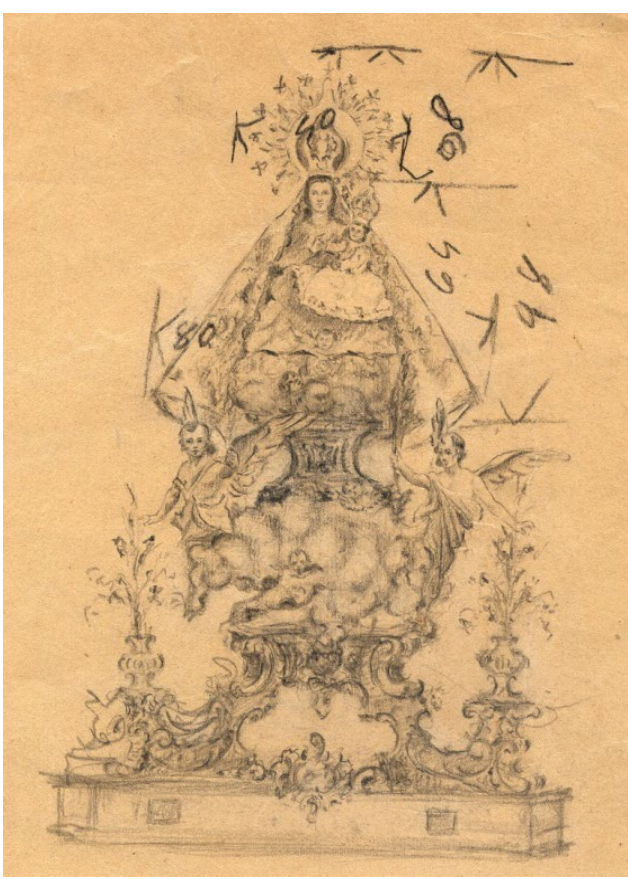

"Virgen" Boceto para paso. Lápiz/papel. 27 × $35 \mathrm{~cm}$. 
existentes entre este escultor y el resto de academias, talleres, estudios, tertulias y artistas que tuvieron relación o estuvieron vinculados a su taller.

Un objetivo esencial será conocer y dar a conocer el gran patrimonio artístico y de artistas, del que disponemos y en muchos casos desconocemos, en Murcia.

Y un tercer objetivo se centra en conocer el sistema y las opciones existentes para el aprendizaje de la escultura y técnicas relacionadas, la edad en que comenzaban y hasta qué edades podían desarrollarse estos estudios y la influencia de los mismos en el panorama artístico de la Región de Murcia. Vinculando y comparando éstos con las posibilidades actuales.

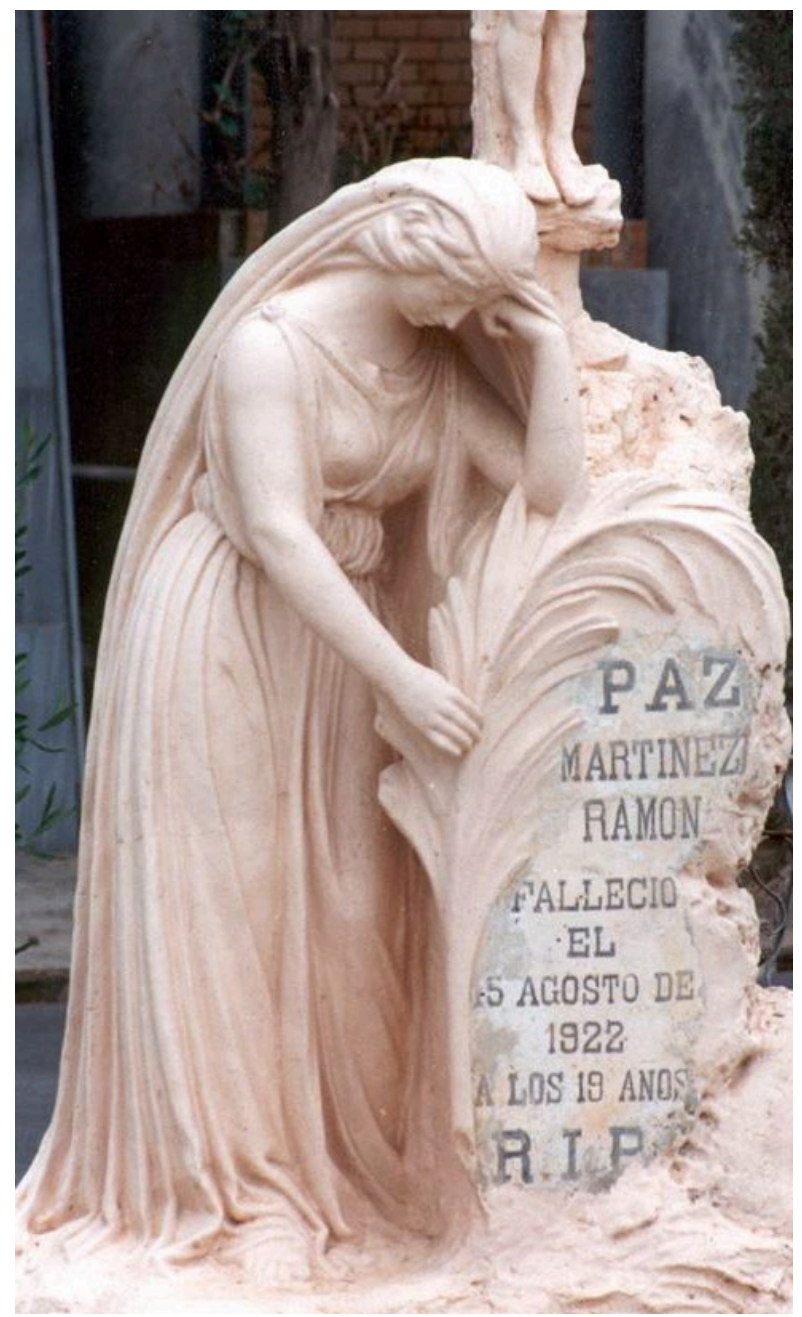

"Paz" Monumento funerario. Piedra. Cementerio de Murcia.

Obras de Anastasio Martínez Hernández (1874-1933).

\section{METODOLOGÍA}

Para la consecución de los objetivos anteriormente citados se han empleado las siguientes estrategias: 1. Recopilación de la documentación existente en libros, periódicos, revistas, webs o cualquier otra publicación o testimonio que aporte nuevos datos que faciliten la búsqueda de obras, fotografías, información o documentos visuales y teóricos. 2. Indagación popular de personas relacionadas con el escultor, la ejecución, conservación o destrucción de estas obras y talleres, así como con aquellos investigadores que se han ocupado de estos temas. 3. Organización y clasificación de la documentación obtenida. 4. Desarrollo empírico de los objetivos.5. Revisión y reestructuración del trabajo realizado. 6. Realización de una conclusión que determine la consecución de objetivos iniciales.

\section{RESULTADOS: ANÁLISIS DE LAS PRINCIPALES ACADEMIAS $Y$ TALLERES}

\subsection{Academia de Bellas Artes de la Real Sociedad Económica de Amigos del País}

Fundada por Salzillo en 1.779 y dirigida por él hasta el fin de sus días en 1.783. En Cartagena en 1833.Continuó vigente a principios del siglo XX. Durante el período estudiado se imparte una enseñanza reglada. La edad mínima para ingresar era de 10 o 12 años. Muchos estudiantes acudían a las clases al tiempo que trabajaban en 
los talleres y muchas veces eran los maestros y no sólo los padres quienes los enviaban a las escuelas considerando que la práctica debía ser completada con los estudios teóricos y de dibujo y modelado que se impartían en la Academia. Para poder pasar a las clases de dibujo, se exigía como formación previa y obligatoria asistir a las clases de Aritmética y Geometría.

En el año 1.900 las clases que se impartían en la Económica eran: Aritmética y Geometría de dibujantes, Dibujo del natural, Clase especial de modelo vivo, clase de dibujo lineal de adorno y topográfico y dibujo de señoritas.

Ejercieron como directores de la Academia desde 1.900: Vicente Pérez Callejas (-1907), Ceferino Pérez Marín (-1919), Elías Tormo, Emilio Díez de Revenga (1922-1924) y como profesores contó la Academia con Federico Mauricio, director de dibujo del natural, Francisco Sánchez Tapia, ayudante escultor, José Antonio Rodríguez, arquitecto, director de la sala de dibujo aplicado a las artes y la fabricación, renunció en 1902; Francisco Sánchez Tapia (-1902), José Giménez Arroniz, director de dibujo lineal y topográfico; Luis Fernández Faustino Millán, Federico Mauricio (-1904), dibujo de figura, modelado y vaciado de adorno; Antonio Meseguer, clase de natural; Alejandro Séiquer (-1921) director técnico de Estudios Artísticos con carácter honorífico. Socio de mérito; Isabel Blanquer Martínez (-1908) y Remedios López Blanquet, fueron directoras de la sala de dibujo para niñas y señoritas; Juan Dorado Brías, auxiliar gratuito de figura, modelado y vaciado; Dolores Manzano Zamora, auxiliar gratuito y Natividad Santamaría profesora suplente sin sueldo de la sala de niñas y señoritas, José Jiménez Arroniz, ayudante escultor y posteriormente sala del natural. Dorado y María Fargas, ayudantes sala del natural; José Calvo García (-1908) , Ceferino Pérez Marín, secretarios; Jerónimo Ros, profesor suplente de la Sala de Dibujo Lineal, de adorno y

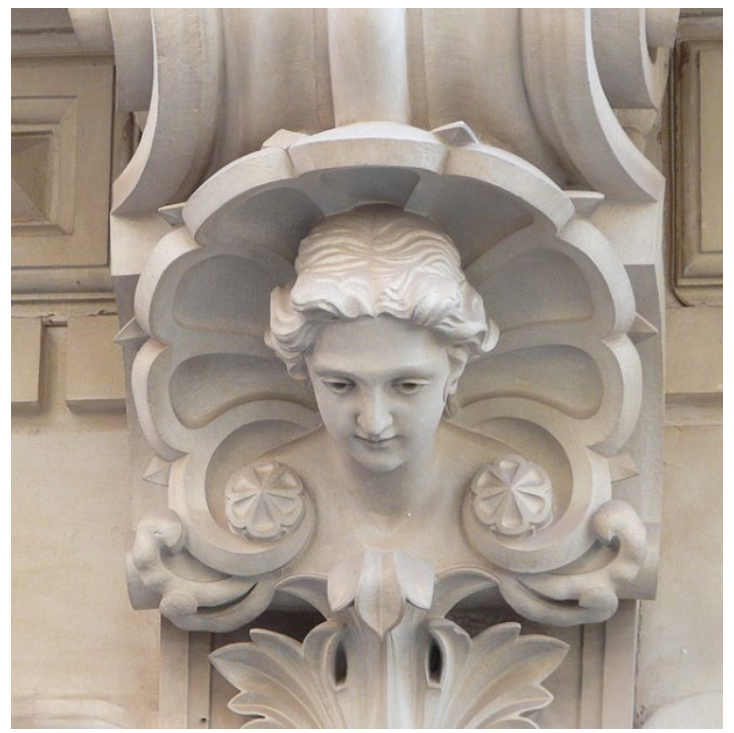

"Detalle de la fachada" Piedra. Museo Modernista de Novelda.

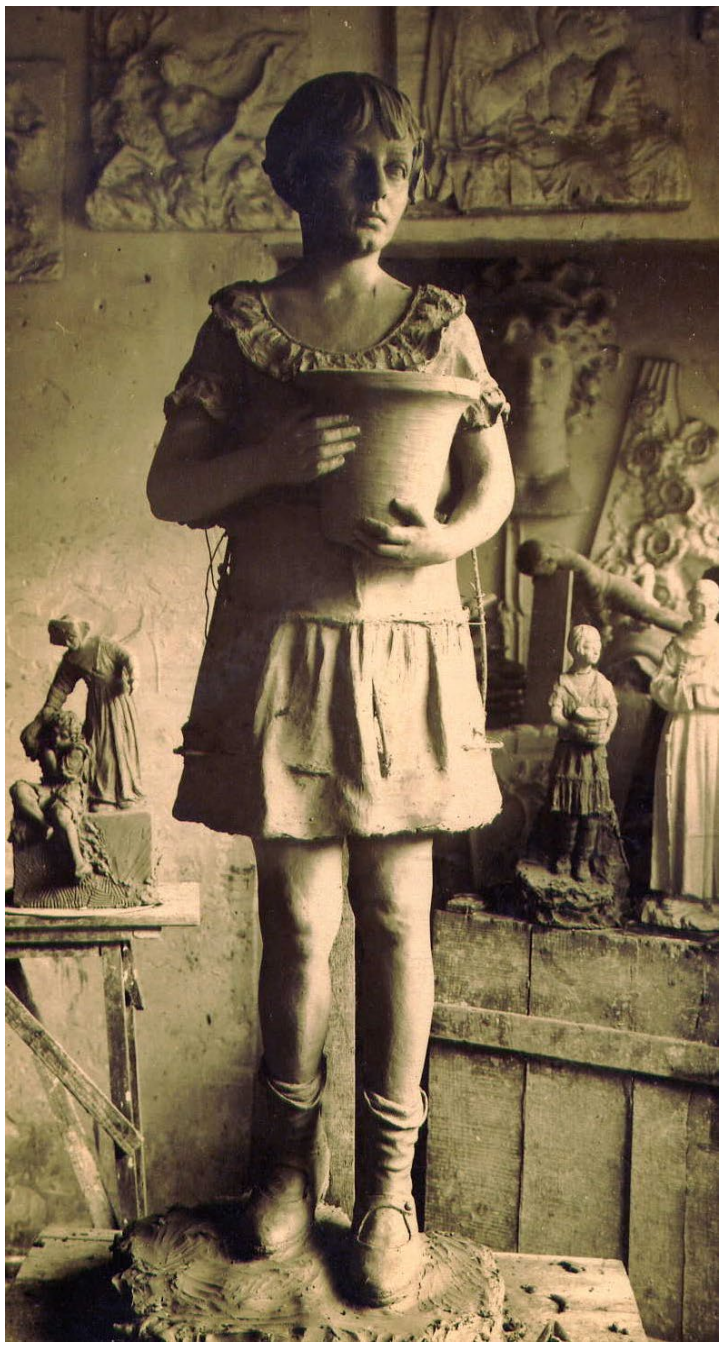

"Niña con cesto" Modelado en el estudio. Aprox. 1925.

Obras de Nicolás Martínez Ramón (1905-1990). 


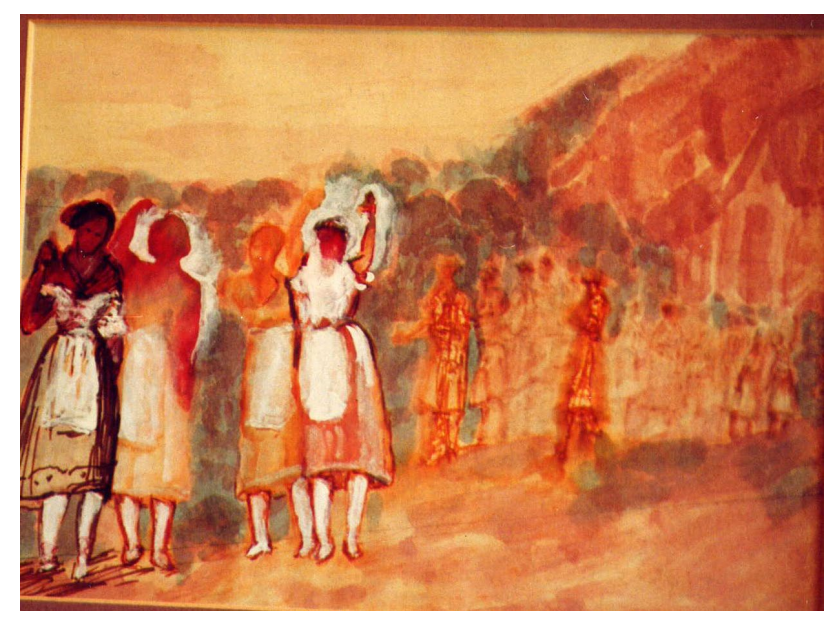

"Escena del Bando" último dibujo realizado, 1990. Col. particular.

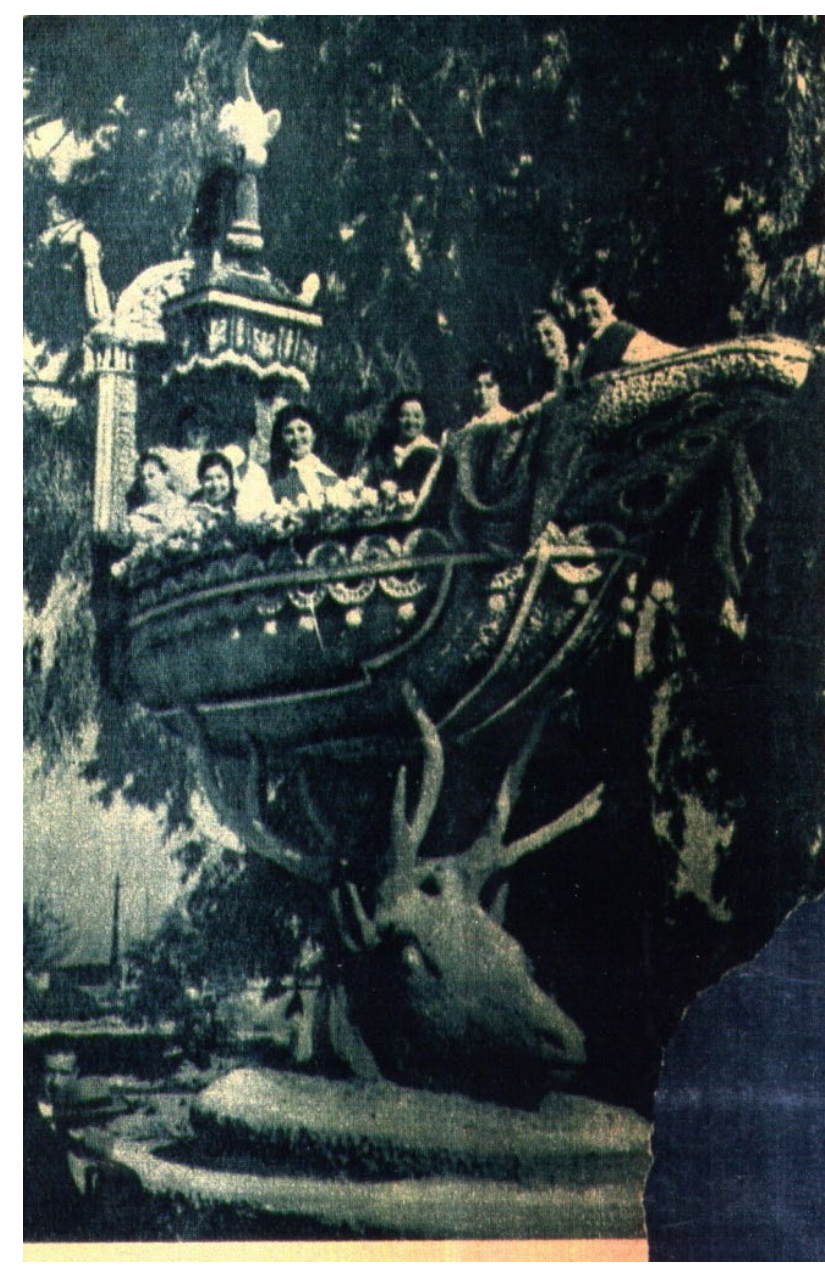

“Carroza Trofeo” Fotografía, 1955.

Obras de Nicolás Martínez Ramón

(1905-1990). topográfico, sin retribución alguna; Antonio Meseguer, profesor de dibujo del Natural; José María Sanz, ayudante de la Sala de Natural. Renuncia en 1915 Jose Antonio Gómez Sandoval, ayudante de la Sala de Natural; Fuensanta Carrasco, profesora suplente de la sala de Dibujo para señoritas; José Seiquer, profesor de escultura hasta el año 1948; Manuel Benavente (1920), profesor de matemáticas. Fueron algunos de los conocidos nombres que impartieron docencia en esta institución.

Durante el curso 1902/03 recibían enseñanza una cifra de 415 alumnos. Durante el curso 1935-36, 425 alumnos. En 1911 el profesorado tenía resuelto dar sus clases hasta el mes de Marzo, sin que del Ayuntamiento ni la Diputación se percibiera un solo céntimo, por lo que se hace imprescindible clausurar la Academia. En 1918 se delibera la reapertura de la Academia para el curso 1917-18 y destacan los buenos deseos de la sociedad frente a los apuros económicos.

En cuanto al Libro de Matrículas aparecen como alumnos en 1901-02, en la clase especial de modelado encontramos que asisten Juan Dorado Brisa, José María Sanz Fargas, José Atienzar Sala, Antonio Viola Bernal, Antonio Nicolás Martínez, Pedro Sánchez Picazo y Manuel Martínez Molla en 1913/14, en las clases de Aritmética y Geometría asiste Anastasio Martínez hijo, 1916-17. Clases de figura, modelado y vaciado de adorno asisten Anastasio Martínez hijo, Clemente Cantos, Joaquín García y José Almela. 18918-19, clases de Dibujo de Figura, modelado y vaciado asiste Anastasio Martínez hijo. 1919-20 a las clases de aritmética y geometría asiste Nicolás Martínez. En 1923-24 a 


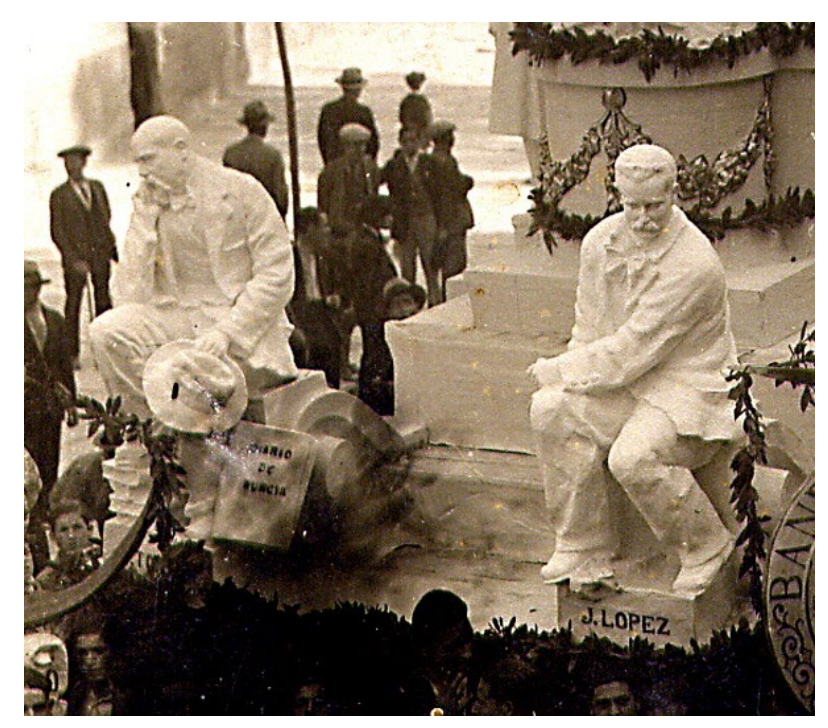

"Carroza para el bando" Detalle. Fotografía.

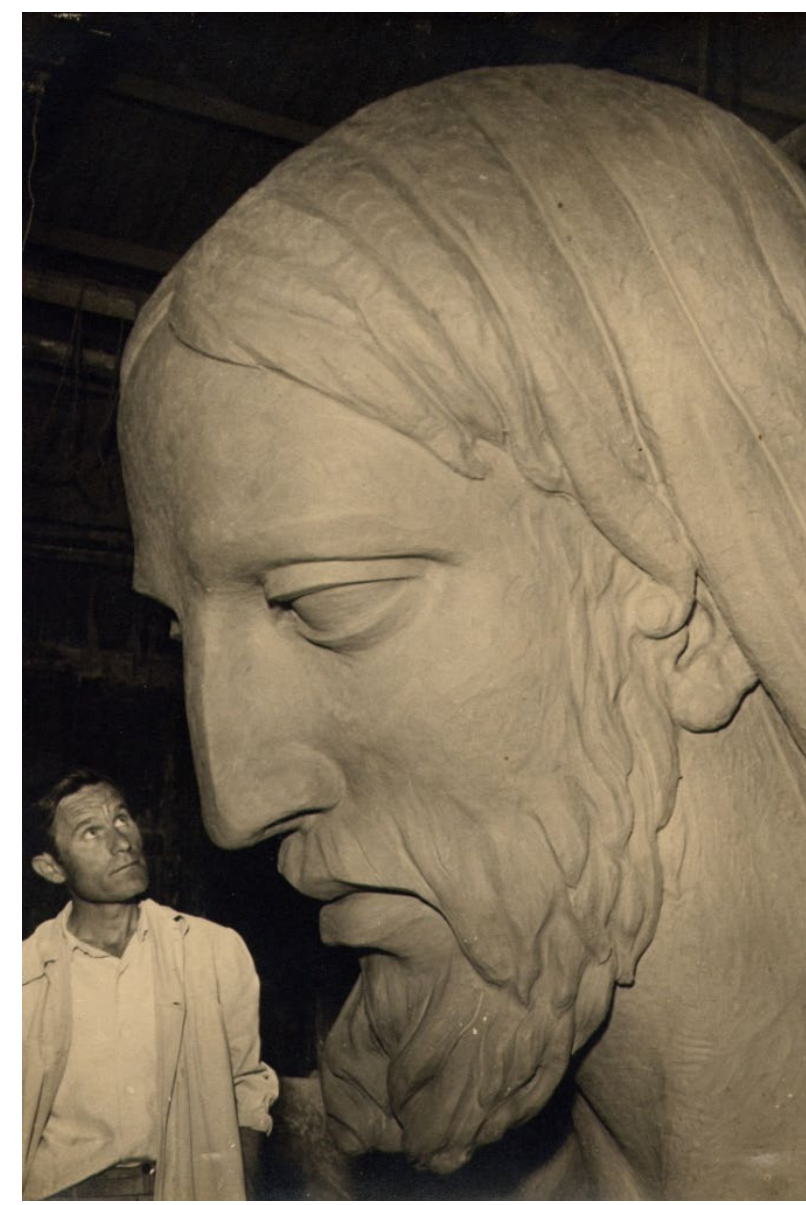

"Corazón de Jesús de Monteagudo"

Detalle del Monumento durante su ejecución en arcilla en el taller junto al escultor.

Obras de Nicolás Martínez Ramón (1905-1990). las clases de Aritmética y Geometría asisten Nicolás Martínez, Antonio Villaescusa y Juan González Moreno.

\subsection{Círculo Católico de Obreros}

Fundada en Mayo de 1892 en una casa ubicada en la calle de San Nicolás, propiedad de Mariano Palarea y Sánchez Palencia, mecenas que donó esta vivienda con el objetivo de "regenerar las costumbres sociales" sin adscripción a ideología o política alguna. En esta academia encontramos las siguientes secciones o clases: Sección de Enseñanza o Junta de Profesores; Sección Dramática; clases de primeras letras, clases de catón, matemáticas, gimnasia, religión, música, dibujo y pintura. Como profesores destacar a José María Sobejano (Murcia 18521918) que durante 20 años ejerce como profesor de dibujo en el Círculo Católico de Obreros, cargo que desempeña de forma gratuita. Como alumnos aparecen entre otros, Anastasio Martínez Hernández, Miguel Soriano, Antonio Nicolás, Victorio Nicolás, José Planes, Clemente Cantos, Nicolás Martínez, Nicolás Rex, Pedro Flores, Fulgencio Saura y Joaquín.

\subsection{Taller de Anastasio Martínez Hernández}

Fundado en Murcia en 1894 por este escultor, que marca el inicio de una nueva etapa en las diferentes facetas del arte, rompiendo con la escuela salzillesca y aportando una nueva visión influido por el mundo clásico. Ubicado primeramente a espaldas del teatro Romea, posteriormente en la calle San Judas (actualmente Gran Vía) y finalmente en la calle Gómez Cortina (calle Aguadores).

Este taller fue fundado por Anastasio, tras su regreso de Madrid, surgió ante la 
necesidad o inexistencia en Murcia de un taller dedicado a la talla, escultura, pintura, artes decorativas en general, incluyendo entre ellas la realización de muebles artísticos, para lo cual, según encontramos en una revista de principios de siglo, con tirada internacional "Les Industries Spagnoles. Publications Internationales Du XXmeSiecle. Section Iberique.Barcelona, Bureaux. p. 10-11" se debía acudir a Barcelona o Madrid. Es un intento de aunar arte y diseño en el día a día, en la vida cotidiana. Considerando el escultor que el arte debe existir en cada parte de la vida, como parte integrante de ésta "el arte nos humaniza y nos diferencia de nuestra parte más animal". Proveniente de una familia no acomodada, de clase media alta, buscando en su vida una actividad que le permitiera desarrollar su creatividad y su dedicación al arte, sin llegar a ser por ello una carga en este mundo. Sin ser un lastre para la sociedad. Una búsqueda del equilibrio entre la /consecución del ideal artístico y su integración en la vida diaria.

Perduró este taller hasta bien avanzado el siglo $\mathrm{XX}$, con él a su cargo hasta su muerte en 1933, fecha en la que su hijo debe hacerse cargo del taller. Durante la Guerra Civil fue requisado y desapareció prácticamente todo, volviendo a emerger en 1939 con su hijo Nicolás Martínez Ramón al frente del mismo.

Posteriormente un desafortunado incendio acabó con gran parte del archivo y la biblioteca existentes. Biblioteca que destacan en numerosas ocasiones conocidos y asiduos al taller del artista, por lo amplia y completa de la misma. Se pudieron rescatar y salvaron varios libros de cuentas de diversos años y una parte importante de los libros y revistas existentes, entre los que se cuentan varios volúmenes de la colección de "La Esfera", importante revista de arte y sociedad de la época, y numerosos libros de escultura de todas las épocas y estilos, entre los que existen láminas impresas con el sello original

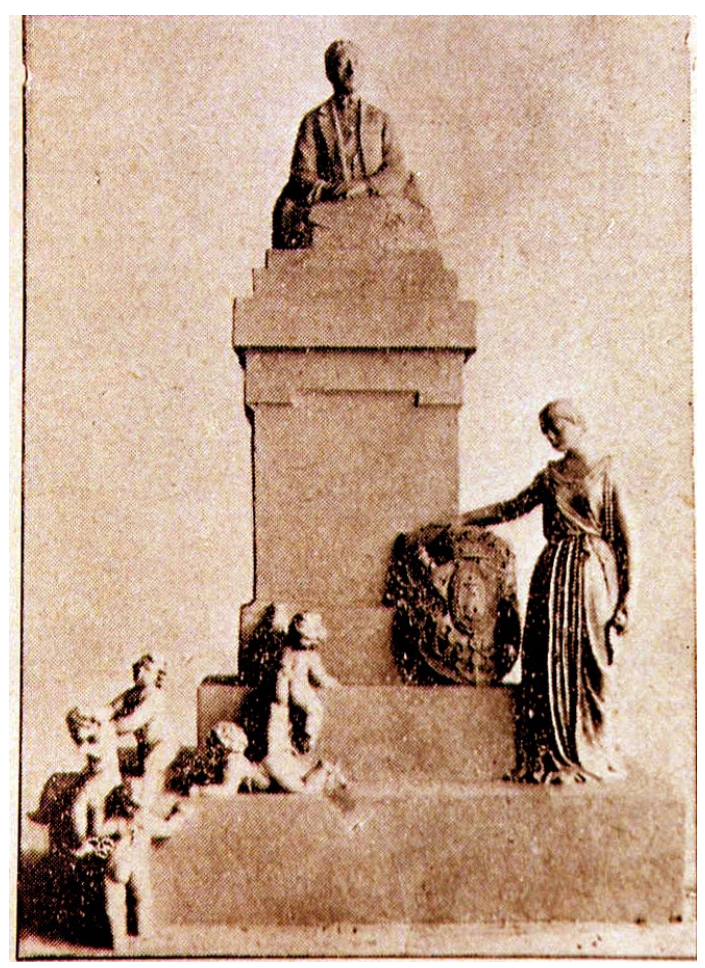

"Monumento a Don Alfonso Torres. Cartagena". Boceto. Obras de Nicolás Martínez Ramón (1905-1990).

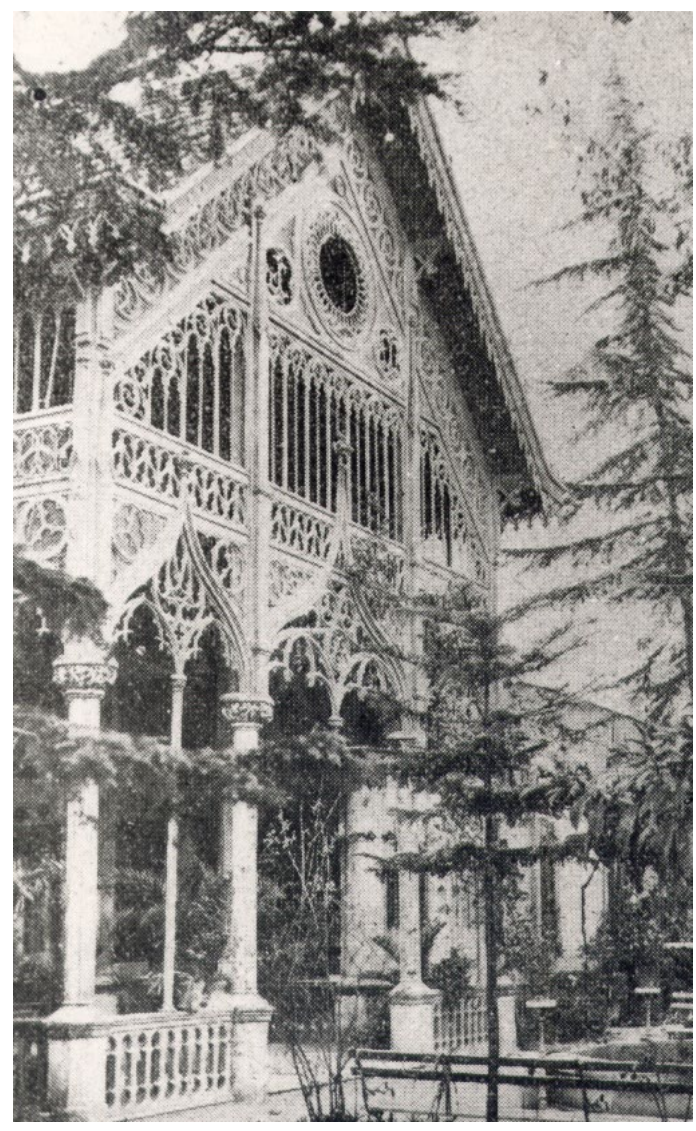

"Cenador de entrada al Recreative Garden" Madera, 1897. Obras de Nicolás Martínez Ramón (1905-1990). 
del escultor italiano afincado en Murcia, Baglietto, libros de escultura monumental española, en especial de Barcelona y Madrid, alemana, inglesa e italiana, lo que confirma sin dejar ninguna duda que se mantenía al corriente de las vanguardias y estilos artísticos de todas las épocas, lugares y disciplinas artísticas. Tienen pues aquí los alumnos y discípulos la posibilidad de consultar con una extensa biblioteca relacionada con temas artísticos y artesanos que les proporcionaba una visión constante de las etapas y tendencias del arte. Hemos de destacar aquí, que este taller lo fue principalmente de arte y artesanía en todas sus facetas. Es, según escribe Cristina Gutierrez "uno de los centros claves para la formación en el oficio durante las tres primeras décadas del siglo", y añade Adela Sánchez Guarinos "donde acudían los que iban a ser los impulsores del renacer escultórico del novecientos murciano".

Además de la realización de obras monumentales, retablos, figuras con diferentes fines en los más diversos materiales, madera, escayola o piedra, uno de sus más destacados valores lo encontramos en su extensa labor docente, allí asisten, como aprendices la mayor parte de los artistas de finales del siglo XIX y la primera mitad del siglo XX. Un taller en el que se contaba con un personal fijo de más de 30 personas, aprendices, artesanos y futuros artistas, que bajo la dirección y supervisión de Anastasio ayudaron en la realización de gran parte de las decoraciones neoclásicas y modernistas de los edificios de Cartagena, Murcia, Almería, Albacete y Alicante, entre otras, una decoración integral, exterior e interior, de los que aún hoy, nos han quedado algunas impresionantes muestras, como puedan ser el Museo Modernista de Novelda, los baños de Fortuna y Archena, o casas particulares como la casa Melgares, Palacete de Fuente la Higuera, casa del Pino o casa Palazón.
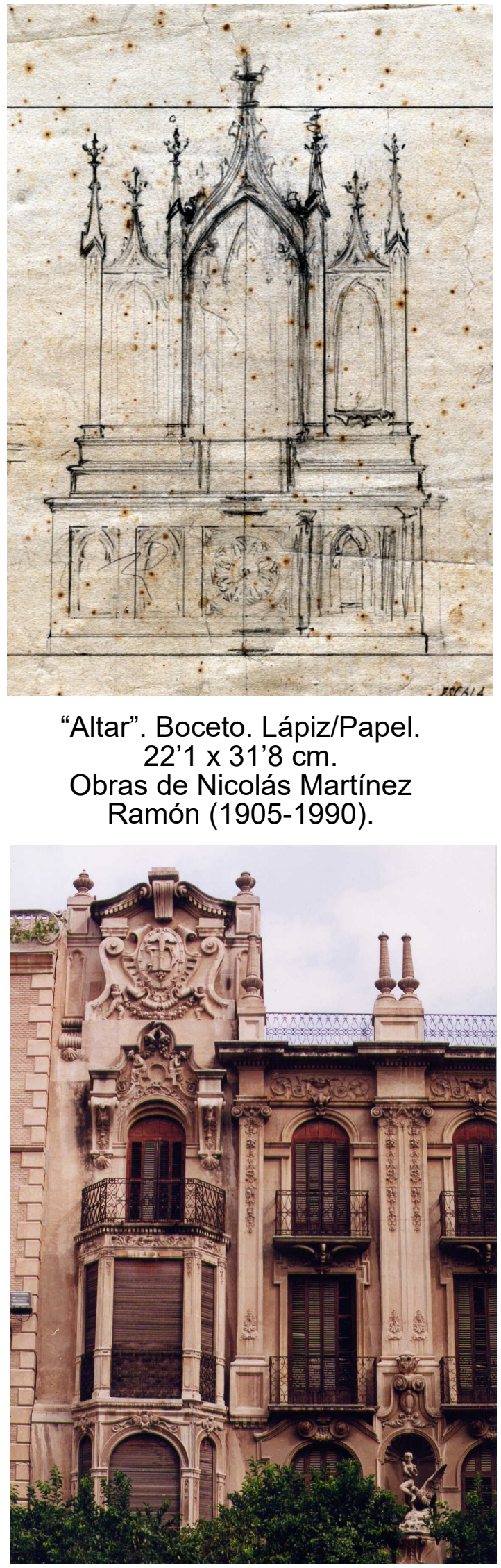

"Decoración de la Fachada" Plaza de los Apóstoles.

Obras de Nicolás Martínez Ramón (1905-1990). 
En este taller comenzaron su andadura artistas de la talla de Nicolás Martínez Ramón (continuador del taller, dedicándolo más a la escultura), José Planes Peñalver (fundador de la Escuela de Artes y Oficios de Murcia), Clemente Cantos y Antonio Garrigós (fundadores del taller de los Bellos Oficios de Levante), Lozano Roca, Antonio Villaescusa, Juan Díaz Carrión, etc... Desembocando posteriormente en el estudio-taller de su nieto, el escultor Anastasio Martínez Valcárcel, donde se ha formado el actual estudio de EQUO 6, ARQUITECTURA, FORMA, LUZ Y COLOR, equipo formado por discípulos directos del taller de Anastasio Martínez, que, junto a otros nuevos componente, abarcan un amplio campo de las artes, arquitectura, escultura, pintura y vidrio, este último abandonado tras la muerte de su principal exponente, la joven artista Blanca Martínez León, fallecida en 2.012 por un lamentable error del destino.

\subsection{Círculo de Bellas Artes}

Se constituye en Murcia en Enero de 1902 sin domicilio. Se ubica posteriormente en el número 2 de la Plaza de Cetina. Al cargo de la presidencia Diego Hernández Illán, en la sección de pintura Alejandro Séiquer, posteriormente presidente del círculo y Sánchez Picazo de la sección de pintura; en la de música Antonio Puig y literaria Ricardo Sánchez Madrigal.

El planteamiento de estas clases era como un lugar de prácticas y reunión, a ellas acudían grupos de pintores y escultores, generalmente procedentes de las clases de la Económica. Existencia desde 1910 de una sala de modelo vivo, una clase con yesos y reproducciones y una biblioteca con revistas como "La Esfera". Las clases de dibujo estaban instaladas en el actual conservatorio y las clases de modelo vivo en los altos del Romeo, en la que se sorteaba el lugar que debía corresponder a cada uno. A estas clases asistieron Victorio Nicolás, Luis Garay, José Planes, Joaquín, Almela, Flores....

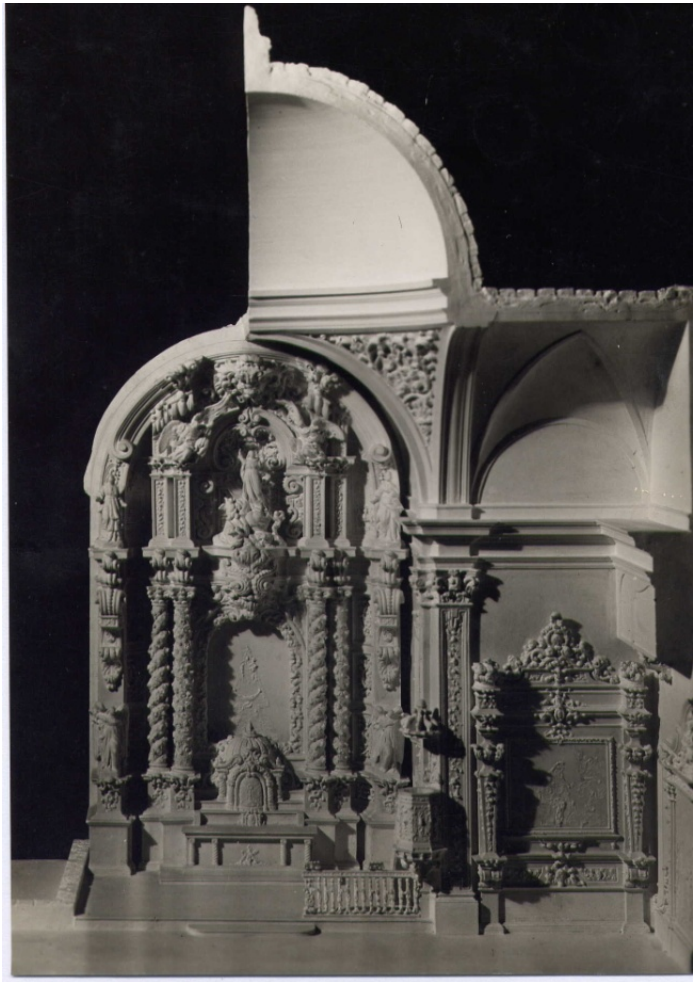

"Boceto concurso capilla de la Fuensanta" boceto. Obras de Nicolás Martínez Ramón

(1905-1990).

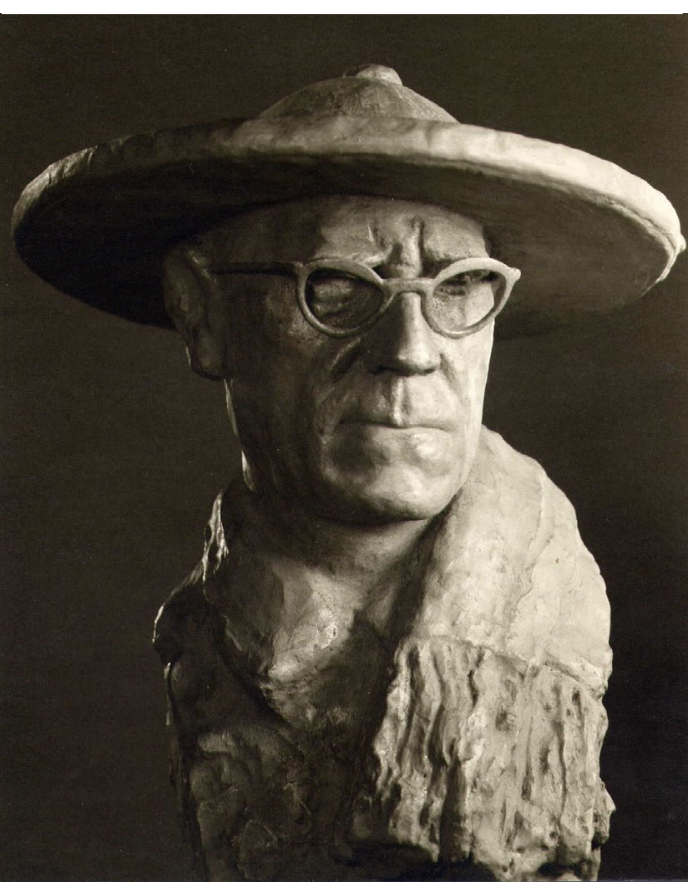

"Retrato de Emilio el de los muebles" 1959.

Obras de Nicolás Martínez Ramón (1905-1990). 
Una buena administración permitió la celebración de exposiciones, conciertos, conferencias, concursos e incluso la creación de pensiones para los artistas. Logrando esto en parte a través de los ingresos por el juego, idea de Don José Hilla.

\subsection{Tertulia del Casino}

Se constituye en Murcia y acuden habitualmente un numeroso grupo de personas relevantes en el ámbito cultural murciano. Incluimos aquí un artículo en el periódico en el Diario de Murcia, El (Murcia) 22-08-1890. p 2 sobre el hombre y la mujer "listos", en los que hace referencia a la concurrencia a las diferentes tertulias de determinados prototipos de personajes:

...Con los que no transige es con los periodistas. De danzantes para arriba, los pone que no se les puede cogerá los pobrecitos. Para él no entienden de nada y de todo hablan. ¡Ya los pondría él a buen recaudo! En el Café no deja hablar a ninguno y es de los más elocuentes de la tertulia del Casino. Regularmente no está afiliado a ningún partido: es solo un patriota, como él dice... A. BALBOA

\subsection{Tertulia de la Confitería Ruiz Funes}

Se constituye en Murcia y a ella asisten asiduamente diversos artistas y miembros de la sociedad de Murcia. En esta ocasión me remito a un artículo aparecido en el diario El Tiempo, (Ed. Mañana) (Murcia) - 15/08/1920, p 2- 4, escrito por Andrés Sobejano:

"Tan efusiva y simpática es esta bondad sin afectaciones, quo flota en la casa como un sahumerio, que trasciende a cuantos la visitan $y$ frecuentan, habiéndose siempre conocido en ella, en el cuarto contiguo a la tienda, tertulia inmemorial y casi permanente, desde que las afinidades de credo realista congregaban en su ámbito a los amigos

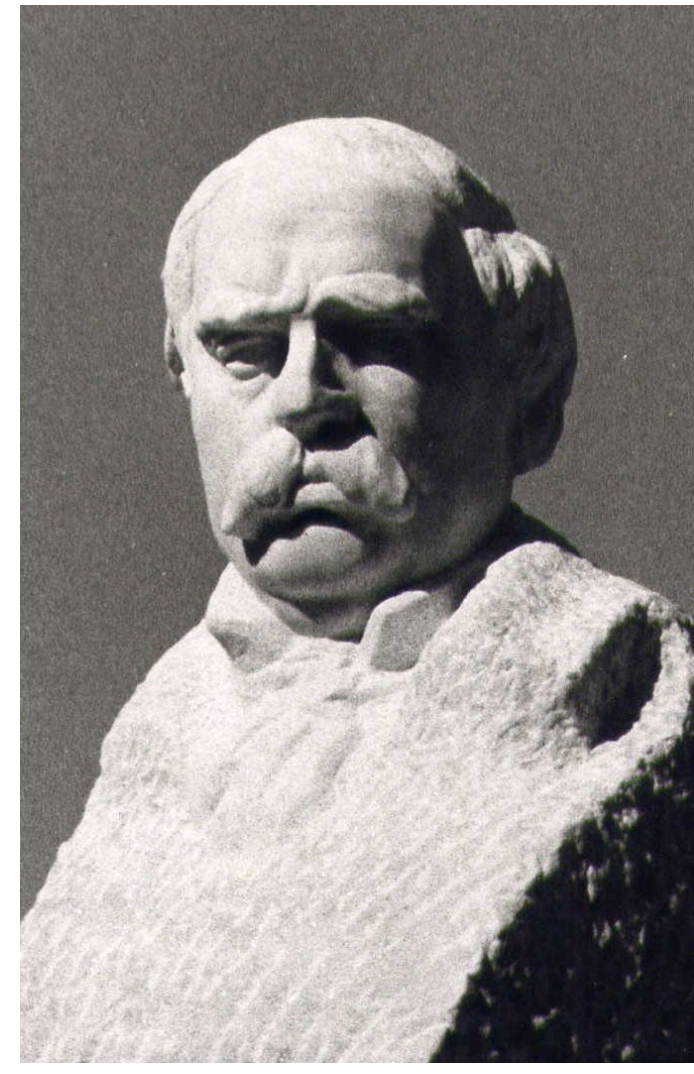

"Retrato de Sebastián Lorente" mármol. 1963.

Obras de Nicolás Martínez Ramón (1905-1990).

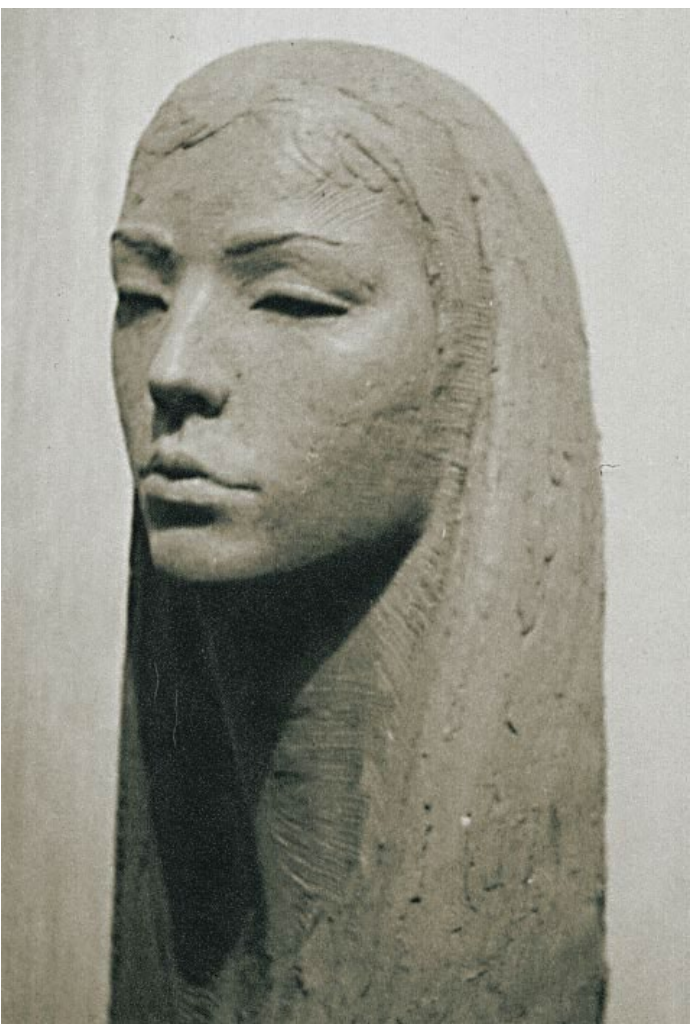

"Retrato de Conchita" colección particular, 1970.

Obras de Anastasio Martínez Valcárcel (1941). 
del tío y del abuelo, que comentaban entra bizcochadas y soconusco las alternativas de revueltas etapas, hasta los tiempos actuales y recientes en que continúalas falanges de amigos leales de toda condición social, preclaros y humildes, profesores y sacerdotes, médicos y abogados, funcionarios y artistas, predominantemente literatos, periodistas y pintores, toda una selecta burguesía de distintas generaciones, la han mantenido con asiduidad, auxiliando muchas veces a la sedentaria tarea de envolver los transparentes y rosados caramelos cuya «clásica longitud» ponderó Benavente en -páginas inolvidables, y aun dejando quizás para las etiquetas la feliz ocurrencia de improvisada rima, y teniendo siempre sólo por aglutinantes la cordial hospitalidad de los generosos dueños, la mutua cortesía, la expansiva conversación que proporciona la actualidad murciana, sin que el chisme doloso. La añagaza política, la irrespetuosa controversia ni la sangrienta burla sean pasto y temas de sus charlas y divertimientos; tertulia que, honrada en muchas ocasiones por personalidades relevantes como al gran Ricardo Gil y presidida casi a diario por el insigne compatriota y maestro Baquero, cobró a veces un tono y una elucubración literatista muy Ramo ouillet, y somatizo muchas otras con la aguda ironía del ingenio local, sin extravíos pedantescos y sin que el Falis se manchase de manteca colmo en la cyranesca hostería de los poetas. Esta amena tertulia en cuya menuda relación habría que citar ya a tantos muertos, este ambiente doméstico, sencillo y noble, han sido siempre como el alma de la confitería."...Andrés Sobejano.

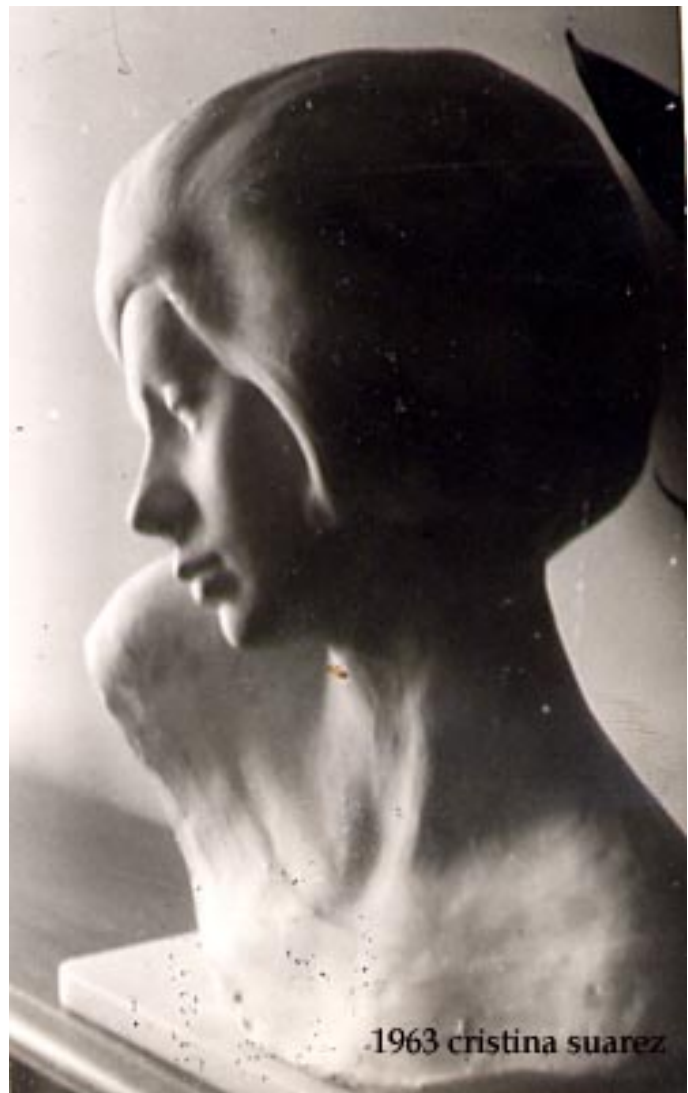

"Retrato de Cristina Suarez" 1963. Colección particular Obras de Anastasio Martínez Valcárcel (1941).

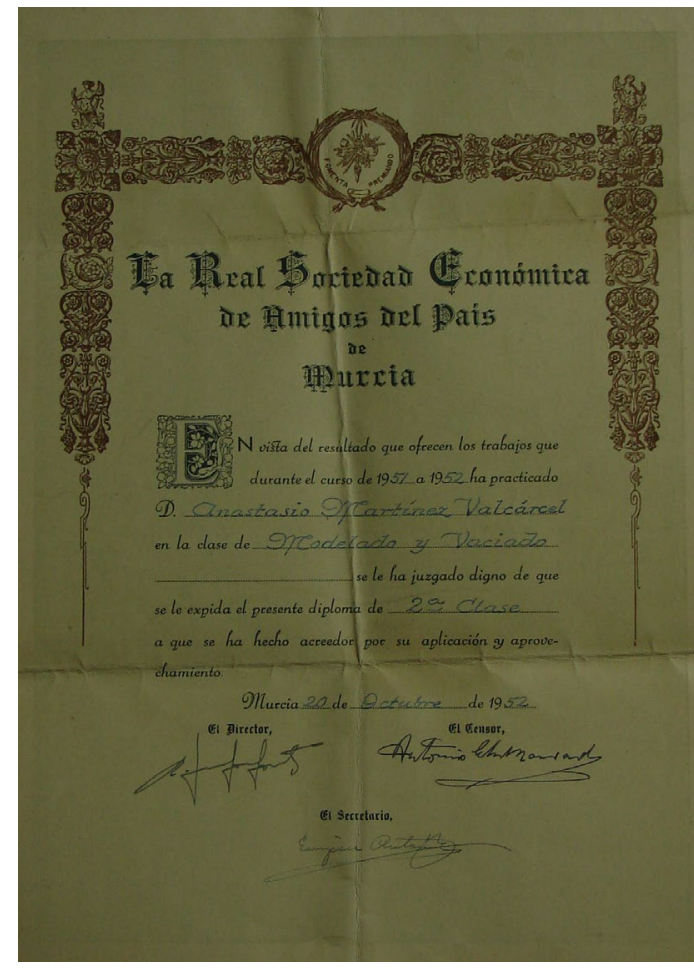

"Diploma expedido por la Real Sociedad Económica" 1952 Concedido a Anastasio Martínez Valcárcel (1941). 


\subsection{Talleres de la c/ del Aire, c/ San Judas, c/ Riquelme y c/de la Gloria}

Se constituye en Murcia en 1916. En estas calles ubicaron sucesivamente el taller un mismo grupo de artistas con poca perdurabilidad en el tiempo. En la calle del Aire, en el edificio renacentista del contraste, trabajaban Garay, Planes, Garrigós, Joaquín, Flores y Victorio Nicolás.

No duró más de dos meses. Era un bajo proporcionado por Nicolás Rex, primo de Planes, quien decide cerrar el taller por la presencia de "mujeres un poco libres" en el taller.

Se señala también como ubicado en la calle de San Judas, pero no podemos confirmarlo con certeza, sí que aquí estuvieron emplazados el taller de Nicolás Martínez Ramón y el taller de Bernabé. Flores señala que de aquí pasaron a la calle de la Gloria, y que en él inició sus pasos Ramón Gaya.

Taller de la calle Riquelme: el grupo había tenido el taller en la calle del Aire. Lugar visitado con frecuencia por Juan Guerrero, Ballester, Dioniso Serra y otros literatos. Abandonaron el lugar como consecuencia de la marcha de Planes a Madrid. Los habituales del contorno de la calle de la Gloria: Garay, Flores, Joaquín, Antonio Garrigós, Clemente Cantos, Ramón Gaya...

Estudio de la calle de la Gloria: grupo que giraba en torno a Garay. Entre los que acudían diariamente figuran Antonio Garrigós "El Miceno", Clemente Cantos, y con menos frecuencia Joaquín, Fuentes, otros visitantes del estudio eran Planes, el acuarelista Victorio Nicolás, Juan González Moreno, Villaescusa, Carlos Rodriguez, Antoni Gómez Cano, Juan Bonafé, Ramón Gaya, Ortiz de Villajos así como Juan Gerrero Ruiz y José Ballester.

\subsection{Taller de los Bellos Oficios de Levante}

Se constituye en Murcia en 1923-1929, en la calle Corvera. En el que trabajaba Antonio Garrigós junto a Clemente Cantos.

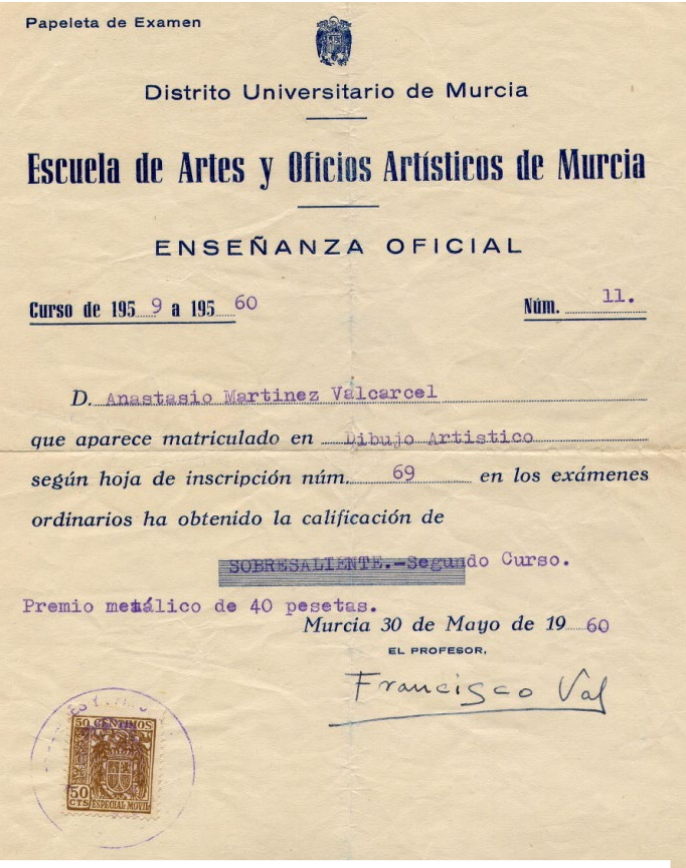

"Calificaciones expedidas por la EAAyOA" 1960

Concedidas a Anastasio Martínez Valcárcel (1941).

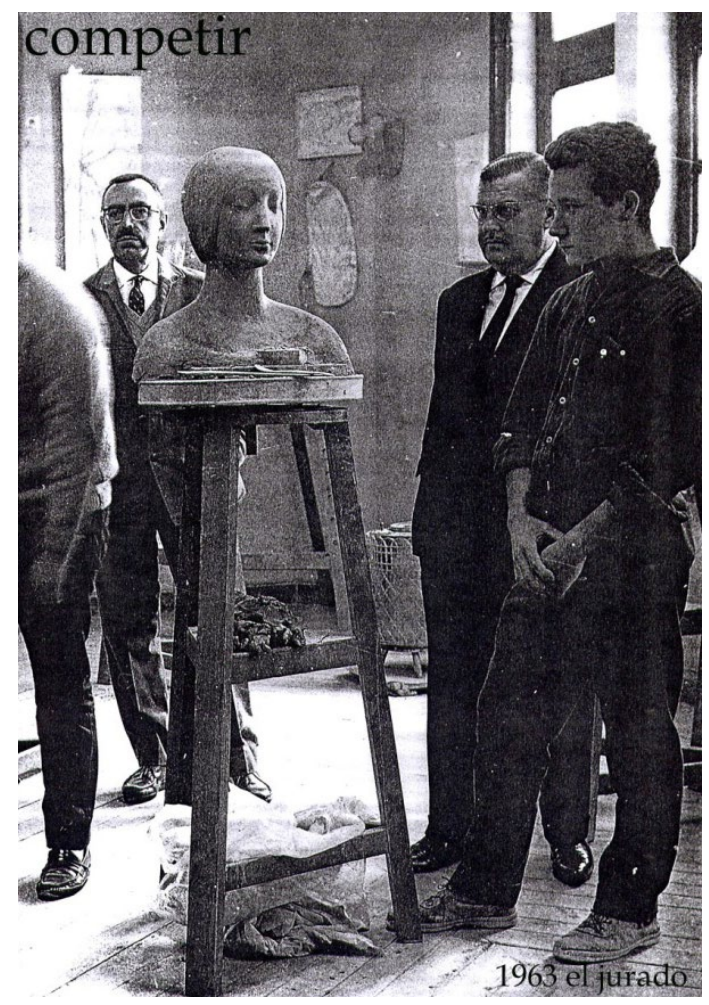

"Concurso Oposición para obtención beca de estudios" 1952. Concedidas a Anastasio Martínez Valcárcel (1941). 


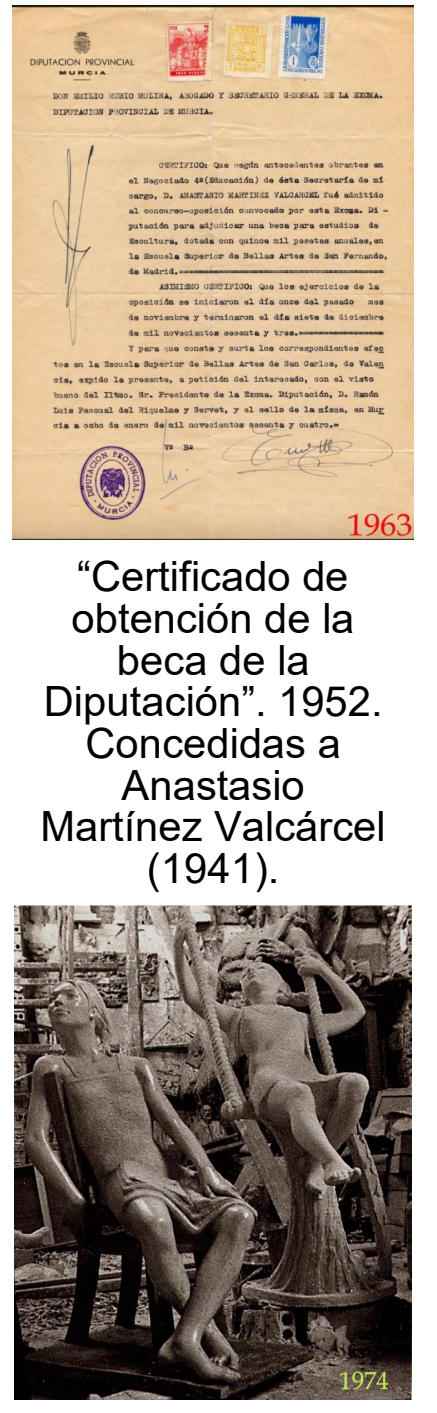

"Columpio" "La Mosca" Piedra.

1970. Estudio de

Aguadores.

Obras de

Anastasio Martínez

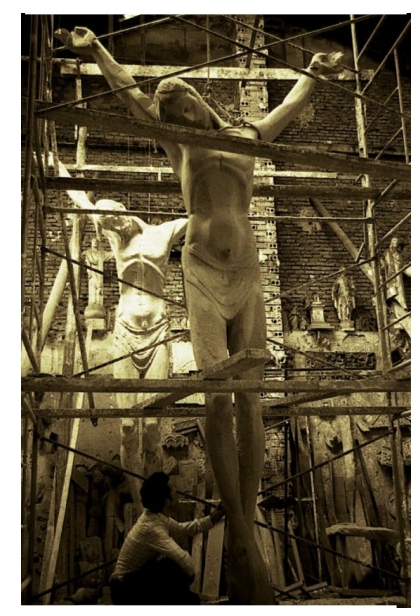

"Cristo" $9 \mathrm{~m}$.

madera 1974. I.

San Pedro,

Valcárcel (1941).
Se hacía una escultura de marcado carácter popular y que se basaba, principalmente, en figurillas de barro con temas de nazarenos, huertanos, etc. De indudable gracia y acierto, unidos a una fina y delicada policromía. Lo destruye un incendio. Garrigós fue concejal de Parques y Jardines.

\subsection{Taller de Nicolás Martínez Ramón}

Se constituye en Murcia en 1933. Recompuesto, tras la Guerra Civil, como continuación del desaparecido de Anastasio Martínez Hernández, se dedica fundamentalmente a la escultura, sin dejar por ello de abarcar gran parte de la escultura decorativa como continuación de la labor de su padre.

Ubicado primeramente en la calle San Judas (antigua Gran Vía) y posteriormente en la calle Gómez Cortina (actual Aguadores) desapareció en la década de los 70 , continuando la tradición, con la tercera generación, esta vez en solitario su hijo Anastasio, que inició su formación en él, al igual que el pintor Dolfo. Manteniendo la tertulia que caracterizó el taller de su padre siendo asidua a ella el pintor Sánchez Alberola, entre otros.

La escultura monumental encuentra uno de sus representantes más significativos en este escultor (19051990). Inicia su educación artística en su ciudad, de manos de su padre, el escultor Anastasio, donde desde muy joven tuvo la oportunidad de conocer todas las vertientes y técnicas del género y los procesos para realizarlas. De él aprendió los principios de las reglas de la proporción, el valor del canon y el dominio de la escala, base esencial de su arte conmemorativo.

Aprendió dibujo en la Sociedad Económica de Amigos del País y en las clases del círculo de bellas Artes, discípulo del pintor Antonio Nicolás, de quien aprendió dibujo y colorido. A los dieciséis años fu enviado por su padre a Madrid como operario de la Casa Granda, a las órdenes de Julio Vicent, dos años después obtuvo una pensión de la Diputación, siendo su presidente Don Antonio Pascual Murcia, para estudiar en la Academia de Bellas Artes de San Fernando.

Regresó a Murcia en 1926 para colaborar con su padre en el primer monumento al Sagrado Corazón de Jesús de Monteagudo, de 10 metros de altura, destruido en la guerra civil. Realizando en 1951 el segundo monumento con 14 metros de altura, que corona el cerro de Monteagudo actualmente. 
Dejaron honda huella en su estilo los diez años de estancia en Madrid. Allí tuvo como maestro a Capuz, con quien trabajó en los talleres Granda; también colaboró con Julio Vicent y conoció a artistas y obras que le hicieron buscar la sencillez en la línea y la eliminación del detallismo narrativo al modo de Vitorio Macho. Para Nicolás Martínez la atención se concentra en lo esencial, como el mismo apuntaba: "lo importante es la masa y los volúmenes, lo demás viene luego". Hay algo en sus monumentos conmemorativos de mayor empaque que le aproxima a la sensibilidad artística de un pintor como Vázquez Díaz o escultores de su generación, quienes al reaccionar frente al modernismo y al gusto arabesco resolvieron los volúmenes en grandes planos dando una sensación de forma hierática. El monumentalismo italiano y alemán de los años treinta y cuarenta dejaron honda huella en sus motivos y concepción artística.

Compaginó su trabajo al frente del taller de su padre, y luego suyo, con la docencia en la escuela de Artes y Oficios, la escuela de Maestría, la sociedad Económica de Amigos del país y el Instituto Saavedra Fajardo.

Durante muchos años ocupó un lugar privilegiado entre los artistas de la tierra, desarrollando una actividad muy intensa tanto en escultura personal, monumental y decorativa, como en la creación de las espectaculares carrozas que le permitían elucubraciones con las que dar rienda suelta a su creatividad en un campo totalmente diferente. Este artista siguió acogiendo, como hiciera su padre tiempo atrás en su taller, aún después de su retiro, a numerosos artistas murcianos que encontraban allí el ambiente propicio para diseñar sus obras con el consejo y ayuda del maestro, o simplemente un lugar de tertulia sobre temas artísticos y contemporáneos de su época.

\subsection{Escuela de Artes y Oficios Artísticos}

La historia de estas enseñanzas va íntimamente unida a la historia de los gremios.

El pilar básico de las artes y los oficios lo encontramos en la Real Orden del 24 de Agosto

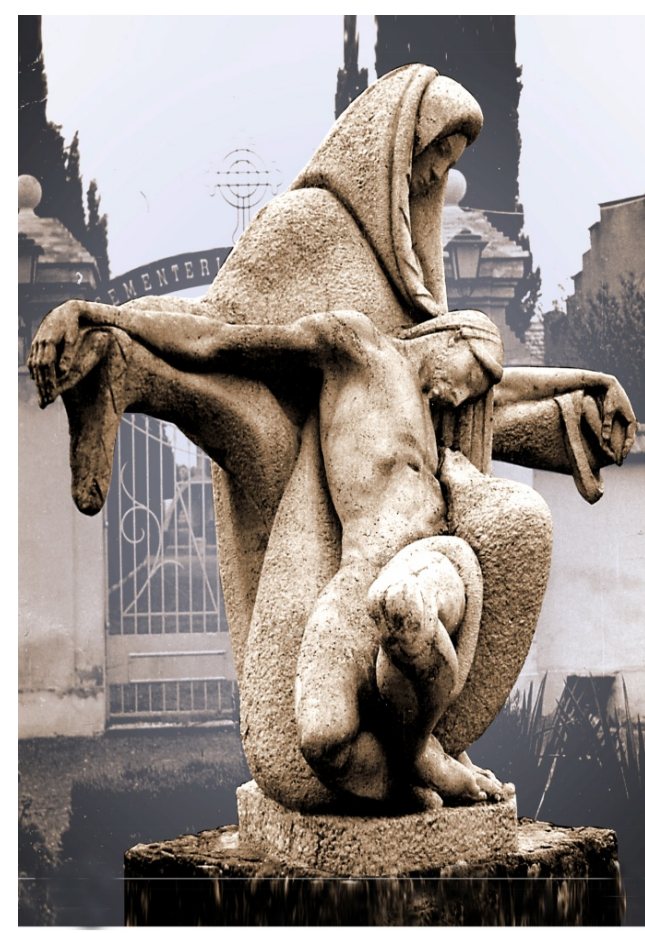

"Piedad" Piedra. 1970. Entrada

Cementerio de Alcantarilla

Obras de Anastasio Martínez Valcárcel (1941).

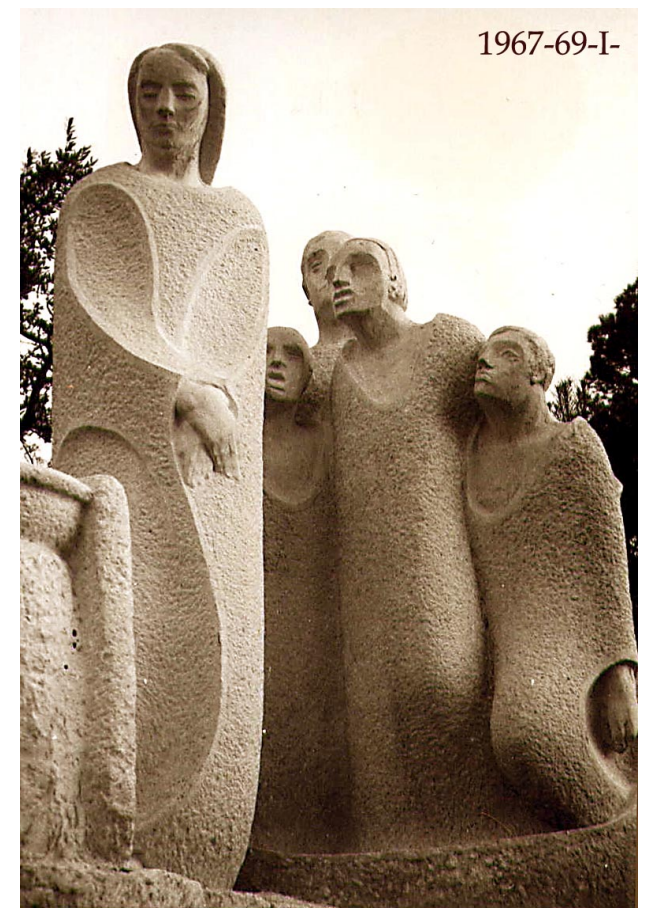

"Parte del Vía Crucis del Paraje de la Santa" Piedra. Totana.

Obras de Anastasio Martínez Valcárcel (1941). 
de 1824. Su primer plan de estudios quedó establecido en 1832 y al finalizar sus cursos se alcanzaba el grado de maestro de Artes y Oficios. El nivel alcanzado por las enseñanzas artísticas españolas en 1895, determinan una serie de reformas entre las que destaca la creación de numerosos talleres, cerámicas, orfebrería, fotografía artística, etc.

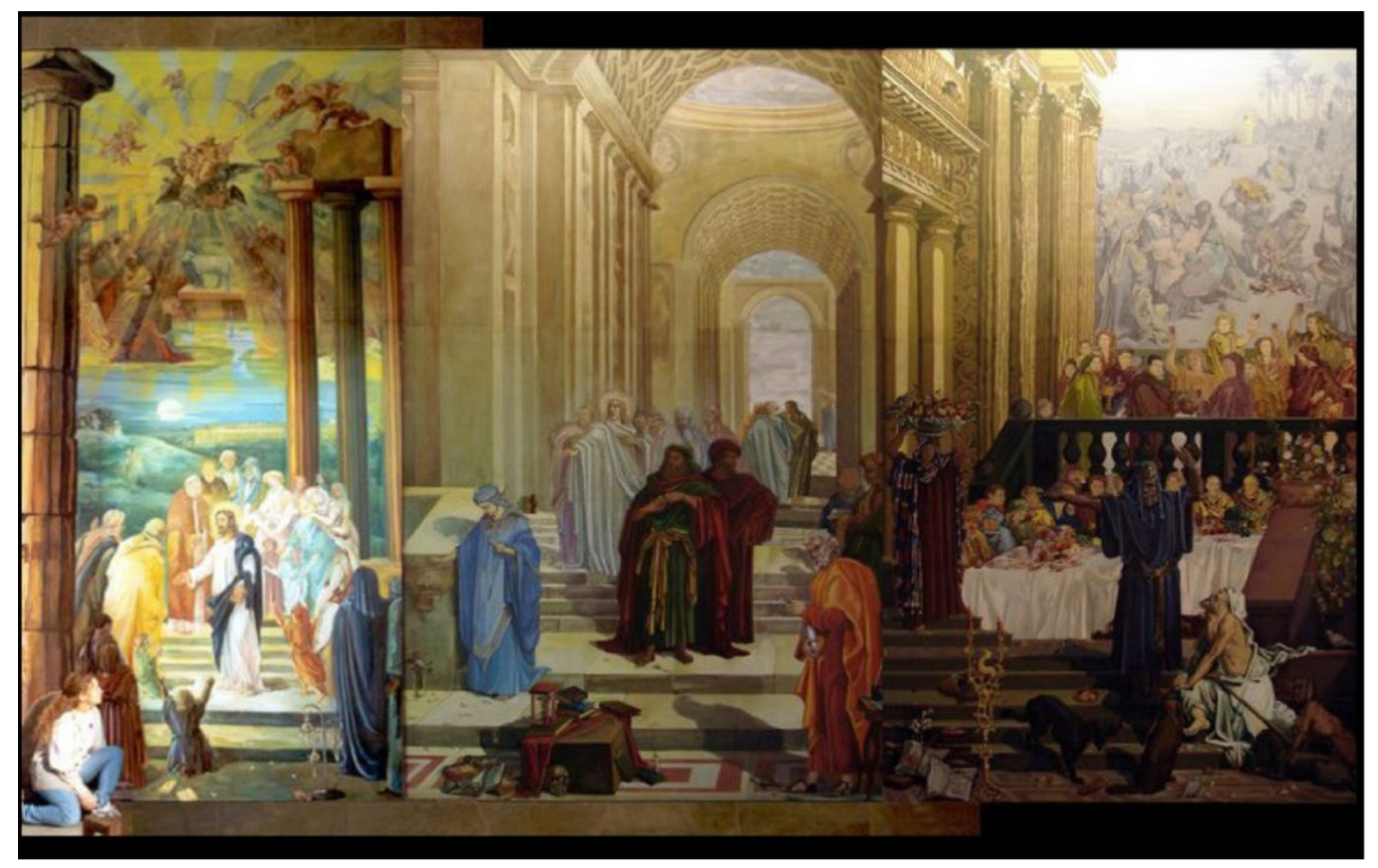

“Parábolas”. Serie de seis murales 1993-1999. Mª Luisa Martínez León.

En Murcia se constituye en 1933 siendo su director José Planes Peñalver, discípulo directo de Anastasio Martínez Hernández. A pesar de las numerosas reformas y cambios realizados y su reciente división en Escuela de Arte y Escuela Superior de Diseño, hoy día continúa activa ofertando ciclos formativos superiores de joyería artística, modelismo y maquetismo, escultura, fotografía e ilustración. Siendo la edad media de los estudiantes entre 18 y 25 años.

La escuela de Murcia, desde sus comienzos, surge para llenar una necesidad de inquietudes artísticas satisfechas en parte por la ya desaparecida "Sociedad Económica de Amigos del País". Instalada en un principio en un viejo edificio de la calle González Adalid, se impartían las enseñanzas de dibujo artístico, dibujo lineal, modelado, gramática y caligrafía, aritmética, geometría y elementos de construcción, bordados y encajes y repujado en cuero.

En las fiestas de Abril de 1935 se organizó una "Semana de Arte", y entre sus actividades el "Primer Salón de Primavera de Pintura y Escultura". En esta exposición presentaron obra prácticamente la totalidad de los artistas murcianos. 


\subsection{Taller de González Moreno}

Juan González Moreno, Murcia 1908 -1996, natural de Aljucer, en 1941 funda un taller de escultura. Dedica gran parte de su obra a la imaginería religiosa, en los que continuaría con los modelos salzillescos. Aunque no fue discípulo directo en el taller de Anastasio, si estaba al tanto de lo que allí se realizaba, debido en parte a su amistad con escultores como José Capuz y Clemente Cantos, tanto como a la utilización de trabajadores de la plantilla del taller de Nicolás Martínez para la realización de moldes y trabajos varios en su taller.

\subsection{Taller de la maestra Campillo}

Ubicado en Murcia, en la calle San Judas, junto al taller de Nicolás Martínez Ramón. Se dedicaba principalmente a la piedra y el mármol, especializándose en decoraciones lapidarias.

\subsection{Taller de Tornel}

Situado en Murcia, en el margen del río, en la carretera que va a la Fuensanta, junto a la vía del tren. Dedicado a la piedra y los trabajos decorativos.

\subsection{Taller de Bernabé}

Especializado en decoraciones lapidarias.

\subsection{Escuela del Malecón}

Se constituye en Murcia en 1935 después de conseguir, Joaquín y un grupo de alumnos que abandonaron la

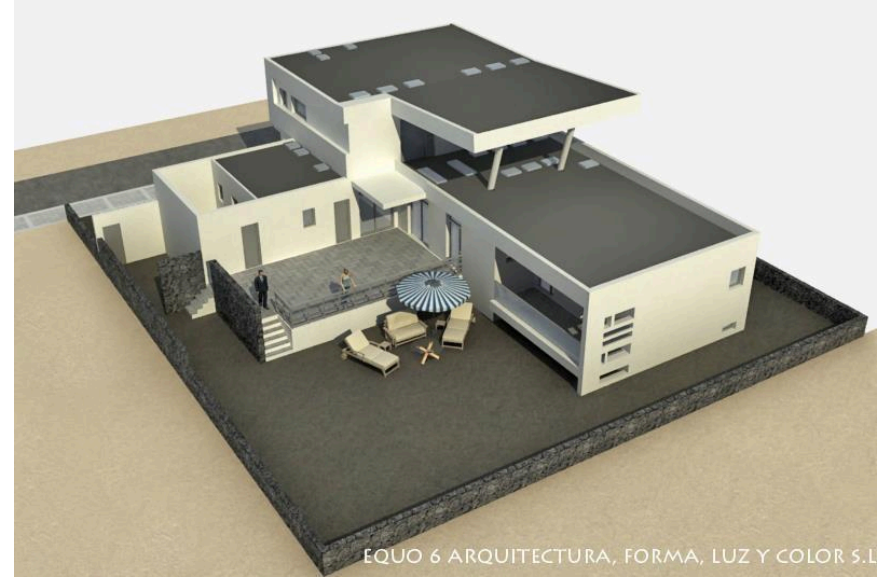

"Vivienda Particular" Natividad Martínez León y Alejandro Córdoba Camacho.

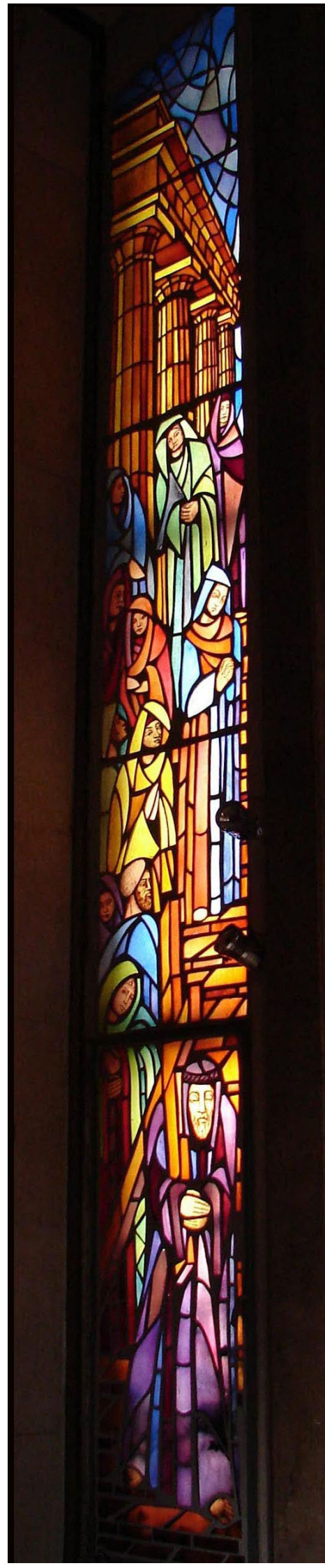

"Vidrieras sobre la Vida de Cristo" 600 x $100 \mathrm{~cm}$. Blanca Martínez León (1977-2012). 


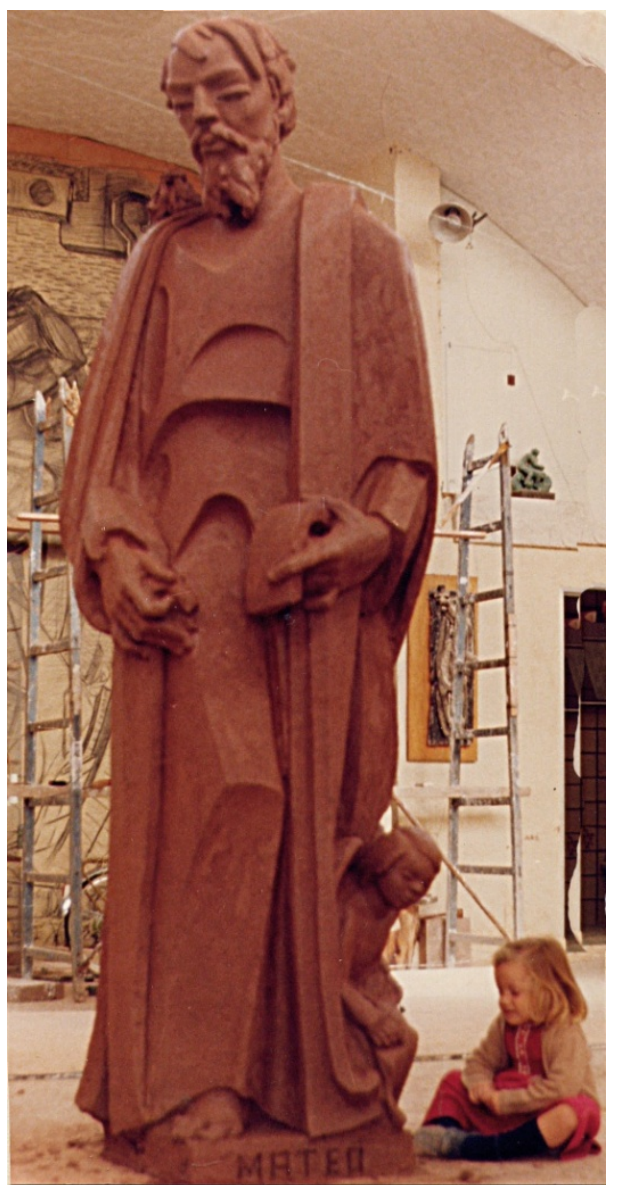

"Apóstol Mateo"

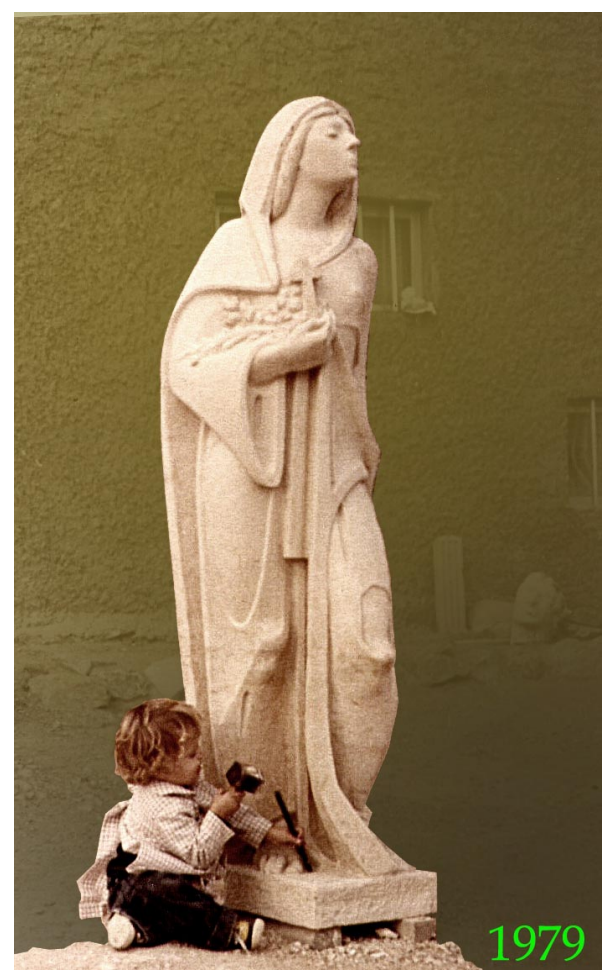

"Descanso eterno" Obras de Anastasio Martínez

Valcárcel. En las imágenes, como aprendiz su hija Blanca, artista vidriera.
Escuela de Artes y Oficios, que el Ayuntamiento de Murcia les cediera un local donde instalar un estudio que se conocería posteriormente como la escuela del Malecón.

Allí acudían y forman el grupo de discípulos de Joaquín: Sofía Morales, Pepita Guaita, Cati González, Cecilia Morote, Vicente Viudez, Román Pérez, José Moreno y Eloy Moreno. No duró más de un año.

Algunos alumnos de la Escuela del Malecón pasan con Joaquín a los altos del Romea, donde realizaban trabajos para el Comité de Agitación y "Propaganda. Los talleres dirigidos por Joaquín idearon todo tipo de creaciones propagandísticas: carteles, rotulaciones, etc. Garay emuló tales actividades, teniendo como local el convento de las Anas.

\subsubsection{Tertulia del café Oriental}

Conocido como Grupo del Café Oriental, se reúnen en un café céntrico de Murcia en el que se daban cita en animadas tertulias, distintos artistas como Clemente Cantos, Victorio Nicolás, Pedro Flores, Luis Garay y Joaquín.

Entre el grupo Garrigós era conocido como el Miceno, una adaptación de la palabra Micenas, ya que Garrigós, debido a la prosperidad de su negocio, solía contribuir generosamente a algunos de los proyectos artísticos del grupo.

\subsection{Estudio de Anastasio Martínez Valcárcel}

Nace en Murcia en 1941. Su formación comienza a una temprana edad, hacia los seis años, alterna los estudios primarios con los de aprendiz en el taller de su padre, Nicolás Martínez Ramón, asumiendo responsabilidades importantes desde muy temprano. Completa su formación con clases nocturnas en la Sociedad de Amigos del País, en la escuela de Artes y Oficios dirigida entonces por Don José Seiquer y posteriormente en la Escuela Superior de Bellas Artes de San Carlos, Círculo de Bellas Artes Valenciano y tras la obtención de una beca de la Diputación Murciana, finaliza sus estudios en la Escuela de Bellas Artes de San Fernando de Madrid. Entre los años sesenta y sesenta y cinco dos hechos, la caída de un andamio y la muerte de su madre marcan un 
encuentro consciente con su obra, que toma gran solidez. En 1968 se independiza para crear su propio taller de escultura, en solitario, rehusando cualquier dependencia de organizar empleados en un taller, lo que según palabras del mismo escultor, no es acorde con su carácter e impide disponer del tiempo suficiente, que él quiere dedicar a creaciones personales. Compagina esta actividad con la enseñanza, que cree básica para mantenerse actualizado con las nuevas generaciones y los movimientos artísticos coetáneos, impartiendo docencia en la escuela de maestría, varios institutos y finalmente en la Escuela de Artes Aplicadas y Oficios Artísticos de Murcia y Orihuela, en esta última como director durante un largo período de tiempo. Formando parte junto a otros discípulos directos de su taller de Equo 6, Arquitectura, Forma, Luz y Color. Nuevamente un suceso acaecido en 2012 incide drásticamente en su vida y obra con la muerte de su hija y artista Blanca Martínez León.

\subsection{Equo 6 - Arquitectura, Forma, Luz y Color}

Se constituye en Murcia en 1990, surge en el taller y a consecuencia del escultor Anastasio Martínez Valcárcel. Un grupo de artistas, que bien inician su andadura $o$ se relacionan posteriormente con el taller deciden unir sus esfuerzos, y a pesar de seguir disciplinas o estéticas diferentes, tener un hilo conductor común a todos. Pudiendo trabajar en contacto y abriendo el campo de posibilidades que ello permite, la realización de los trabajos puede ser o no conjunta. Cada uno continúa su particular forma de hacer y disciplinas artísticas diferentes, escultura, pintura, vidrio, arquitectura... y une sus esfuerzos en composiciones en equipo. Como hemos dicho anteriormente, la muerte de uno de sus miembros más jóvenes en 2012, Blanca Martínez León, supone un duro golpe en lo personal y en lo profesional.

\section{CONCLUSIONES Y DISCUSIÓN}

El objetivo planteado al iniciar este trabajo consistía en el intento de una primera

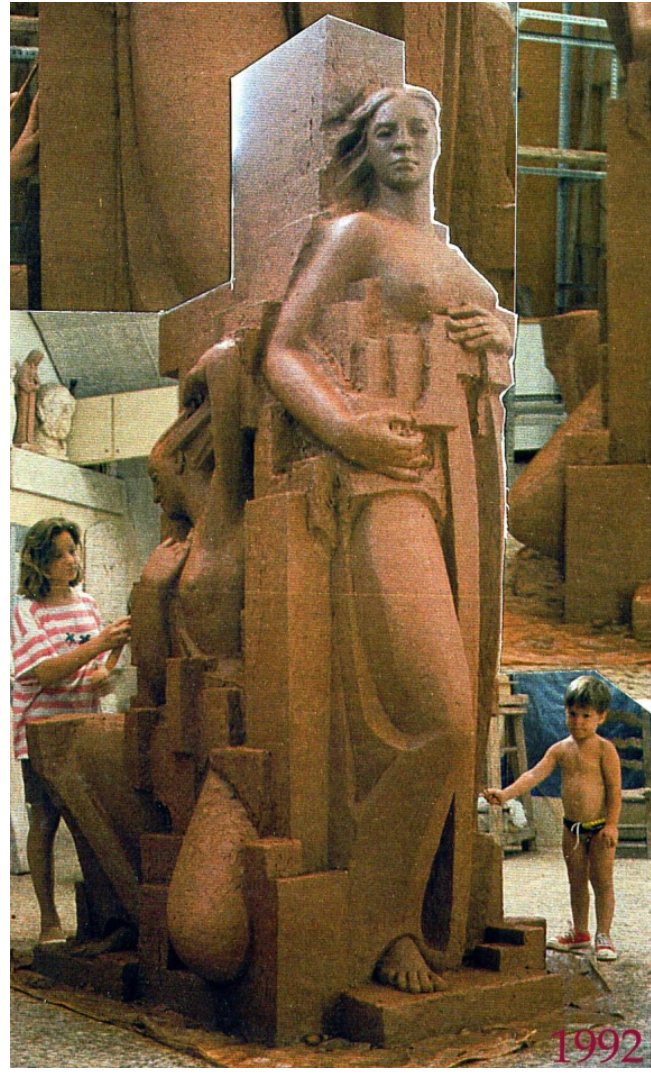

"Alegoría a la ciencia" Facultad de Agrónomos. Orihuela. Obra de Anastasio Martínez.

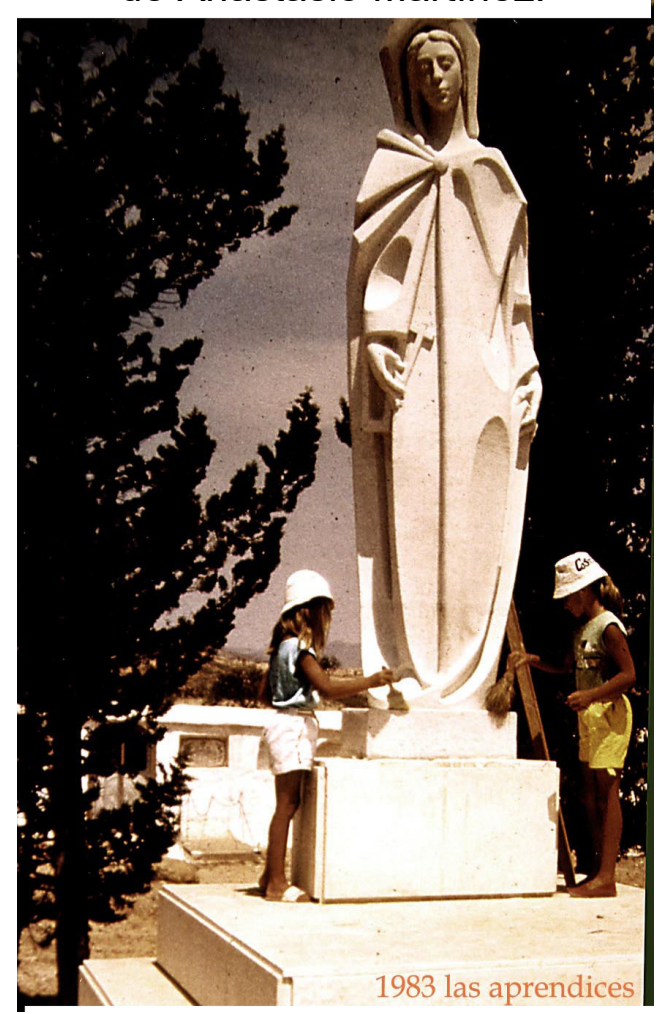

En las imágenes, como aprendices tres de sus hijos Blanca, Anastasio y Luisa "Monumento Funerario". 
recopilación sobre las enseñanzas artísticas, principalmente la escultura, en Murcia, desde finales del siglo XIX hasta nuestros días.

Podemos concluir este artículo destacando la necesidad de un estudio mucho más amplio de la labor realizada en Murcia por diferentes talleres, academias y escultores que realizaron una ingente labor docente y profesional dentro y fuera de nuestras fronteras, que influyeron e influyen en el desarrollo del arte en nuestra región y que, aún hoy día, son desconocidos, ignorados, olvidados... por una gran mayoría de murcianos que permanecen ajenos a la amplitud, la trascendencia y el alcance de sus raíces y la repercusión del arte $y$ de sus artistas, dentro y fuera de Murcia.

Creemos igualmente importante destacar la necesidad de establecer unas enseñanzas, que comprobamos, si existieron en otros tiempos, y que permitan de nuevo el desarrollo del Arte en nuestra Región. No como personas que determinan que somos genios que directamente acceden a enseñanzas superiores, únicas enseñanzas existentes actualmente en nuestra región, (Escuela Superior de Arte, Facultad de Bellas Artes) sino sintiendo la necesidad de crear unas enseñanzas básicas y medias que nos permitan acceder a las superiores con el nivel adecuado, que nos lleven al aprendizaje de este lenguaje, que es el arte. Partiendo de la idea esencial de que el ARTE es un LENGUAJE, que como tal, puede aprenderse, enseñanzas artísticas, y que es el uso que de él se haga, (qué se expresa y cómo se expresa), el que determine que la forma y el contenido, pueda ser considerado ARTE. Y para ello es necesario que exista la posibilidad de aprender este idioma desde una temprana edad. 


\section{REFERENCIAS}

\section{$\underline{\text { Libros: }}$}

Aragoneses, M. J. (1965). Pintura Decorativa en Murcia, siglos XIX y XX. ValenciaMadrid: Sucesores de Nogues.

Baquero-Almansa, A. (1913). Los profesores de las Bellas Artes Murcianos. Madrid: Sucesores de Nogues.

Cegarra-Beltrí, G. y Sánchez-Espinosa, E. (2013). Arquitectura Modernista en la Región de Murcia. Madrid: Libros Mablaz.

Gran Enciclopedia de la Región de Murcia, Tomos 1 a 8. (1913). Murcia: Ediciones Ayalga.

Gutierrez-Cortines, C. et al. (1980). Historia de la Región de Murcia. Tomo X. Enciclopedia. Murcia: Ediciones Mediterráneo.

Historia de la Región de Murcia, Siglos XIX y XX, (1980). Murcia: Ediciones Mediterráneo.

Martínez-León, M. L. (2001). Investigación Metodología del Proceso Creativo Originado en el Taller del Escultor Anastasio Martínez Hernández y su continuación hasta nuestros días. Trabajo de Investigación. Tesina. Valencia: UPV.

Melendreras-Gimeno, J. L. (1999). Escultores Murcianos del siglo XX. Murcia: Compobell.

------- (1998). Escultores Murcianos del siglo XIX. Murcia: Compobell.

------- (1997). La escultura en Murcia durante el siglo XIX: Murcia: Compobell.

------- (1992). El escultor murciano José Planes Peñalver. Murcia: Compobell.

(1980). Monteagudo, sus castillos y sus monumentos. Murcia:

Oliver, A. (1952). 1900-1950. Medio Siglo de Artistas Murcianos. Escultores, pintores, músicos y arquitectos. Valencia-Madrid: Nueva Imprenta Radio.

Sánchez-Albarracín, M. T. (2000). La Carroza, un legado de arte efímero. Batalla de Flores en Murcia (1899-1977). Tesis Doctoral. Murcia: Facultad de Letras.

Sánchez-Guarinos, A. (1990). Las Academias de Arte, Estudios y Talleres en Murcia 1900-1936. Trabajo de Investigación. Tesina. Valencia: UPV. 


\section{Artículos en revistas:}

Andreu-Oller, J. (1913). Industrias Artísticas: Anastasio Martínez. Tallista, Decorador en Madera, Piedro, Yeso y Cartón Piedra. Mueble de Lujo y Artísticos. En ,Les Industries Spagnoles. Publications Internationales Du XXmeSiecle. Section Iberique, pp. 10-11. Barcelona, Bureaux.

Balboa, A. (1890). El hombre listo. El Diario de Murcia del 22 de Agosto de 1890, p. 2.

Cano-Benavente, J. (domingo 27 de marzo de 1988). Recreativo Garden, del que nunca más se supo. En Semanario Murciano, La Verdad $n^{\circ} 188$, II época. p. portada y resto suplemento.

El Diario de Murcia (1901). La Piña. (Tertulia del Café La Piña del Siglo). En El Diario de Murcia del 29 de Enero de 1901. p. 2.

López Guillamón, I. (1990). José Sánchez Lozano, o la continuidad de la imaginería murciana, una aproximación a su obra.

López-Higuera Seiquer, V., Barnuevo M. y Fernández Delgado, M. (1983). 30 + 15 Exposición de pintores y escultores profesores de las Escuelas de Artes Aplicadas y Oficios Artísticos, Revista conmemorativa del 50 aniversario de la Escuela de Artes Aplicadas y Oficios Artísticos.

Sastre-Guarinos, A. (1991). Talleres y estudios de bellas Artes en Murcia durante el primer tercio del siglo XX. Murguetana, 83. Real Academia Alfonso X el Sabio. Murcia.

Sobejano, A. (1920). Ruiz Funes. En diario Murciano, El Tiempo (Ed. Mañana) del 15 de Agosto de 1920. p. 2.

$\underline{\text { Recursos electrónicos: }}$

Anastasio Martínez Valcárcel. Región de Murcia Digital: Recuperado de http://www.regmurcia.com/servlet/s.SI?sit=c,373,m,1207\&r=ReP-13559DETALLE REPORTAJES

Anastasio Martínez Valcárcel. Creaciones Artísticas y Labor Docente. Región de Murcia Digital: Recuperado de http://www.regmurcia.com/servlet/s.SI?sit=c,373,m,1207\&r=ReP-13560DETALLE REPORTAJESPADRE

Ferrándiz-Araujo, C. (2013). La labor pedagógica y científica de la Real Sociedad Económica de Amigos del País de Cartagena. Recuperado de http://www.regmurcia.com/docs/murgetana/N085/N085 004.pdf

José María Sobejano. Región de Murcia Digital. Recuperado de https://www.regmurcia.com/servlet/s.SI?sit=c,373,m,1207\&r=ReP-1620DETALLE REPORTAJES 
Nicolás Martínez Ramón. Región de Murcia Digital. Recuperado de http://www.regmurcia.com/servlet/s.SI?sit=a,87,c,373,m,1935\&r=ReP-13546DETALLE REPORTAJES\&rs=efe1012

Moreno-Fernández, L. M. El círculo de obreros y el sindicato obrero "San José" de Murcia (1890-1923). Recuperado de http://www.regmurcia.com/docs/murgetana/N082/N082 006.pdf

Pujante-Guilabert, P. R. Los relieves del patio pompeyano del Casino de Murcia: obra del escultor Anastasio Martínez Hernández. Congreso de Jóvenes Historiadores de Arte. Recuperado de http://www.murciaturistica.es/webs/museos/marquesina/MQS 96326.pdf

Sastre-Guarinos, A. Talleres y Estudios de Bellas Artes en Murcia durante el primer tercio del siglo XX. Recuperado de:

http://www.regmurcia.com/docs/murgetana/N083/N083 008.pdf 